\title{
UNIVERSITYOF
}

FORWARD

THINKING

WESTMINSTER用

WestminsterResearch

http://www.westminster.ac.uk/westminsterresearch

\section{COMPARING 3D NETWORK BASED COGNITIVE URBAN VOLUMETRICS:An empirical comparison of 3D transport geography and space syntax pedestrian spatial models' effectiveness in a large-scale indoor and outdoor multi-level built environment.}

\section{Lingzhu Zhang and Alain Joseph Franck Chiaradia}

This is a copy of the accepted author manuscript of the following article: Lingzhu Zhang and Alain Joseph Franck Chiaradia 2022. COMPARING 3D NETWORK BASED COGNITIVE URBAN VOLUMETRICS: An empirical comparison of 3D transport geography and space syntax pedestrian spatial models' effectiveness in a large-scale indoor and outdoor multi-level built environment. Environment and Planning B: Urban Analytics and City Science DOI:10.1177/23998083211070567. The final definitive version is available from the publisher Sage at:

\section{https://doi.org/10.1177/23998083211070567}

(C) The Author(s) 2022

The WestminsterResearch online digital archive at the University of Westminster aims to make the research output of the University available to a wider audience. Copyright and Moral Rights remain with the authors and/or copyright owners. 


\section{Environment and Planning B: \\ Urban Analytics and City Science}

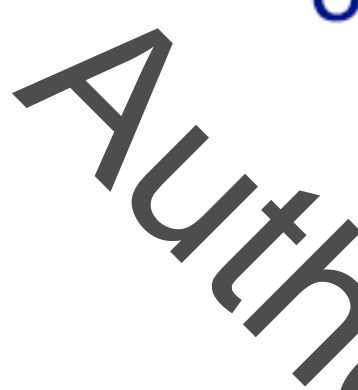

COMPARING 3D NETWORK BASED COGNITIVE URBAN VOLUMETRICS:

An empirical comparison of 3D transport geography and pace syntax pedestrian spatial models' effectiveness in a large-scale indoor and outdoor multi-level built environment.

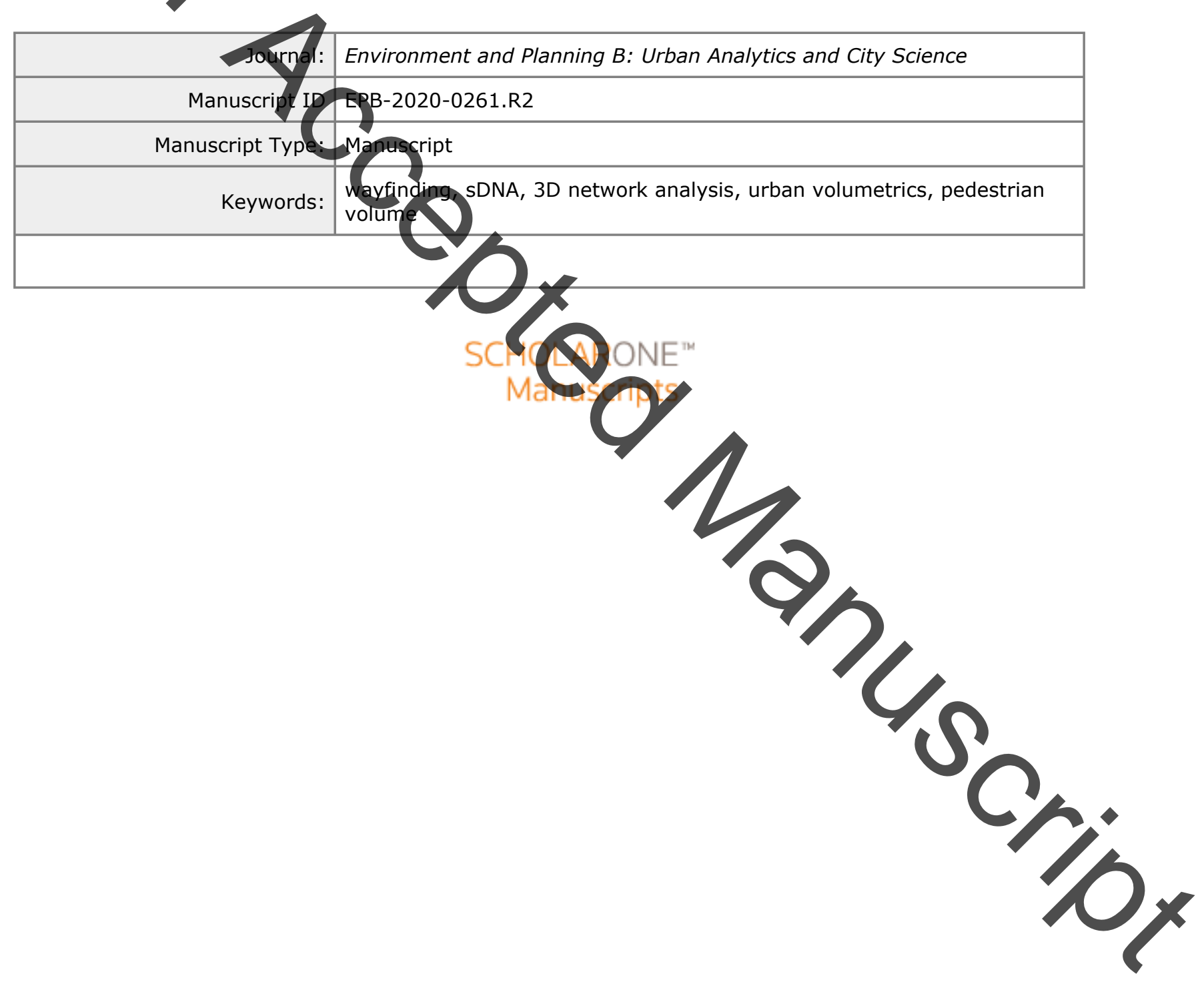


How 3D complex network volumetrics improve analysis

2

3

4

5

6

Abstract

Route choice, wayfinding behaviour and pedestrian movement pattern research relies on objective spatial configuration model and analysis, to quantify and control route choice and wayfinding complexity/difficulty for 3D indoor and outdoor multi-level buildings and urban built entrironments (IO-ML-BE). Our contribution is to compare the interaction of the level of definition (LOD) of indoor and outdoor multi-level pedestrian network spatial models and complexity analyses. Most studies are indoor or outdoor and oversimplify multi-level vertical connections. Using an open data set of a large-scale 3D pedestrian network spatial model that follows transport geography data model, nine spatial models and twelve spatial analyses of a large-scale 3D IO-ML-BE are empirically tested with observed pedestrian movement patterns $(\mathrm{N}=17,307)$. Bivariate regressionanalyses show that the association with movement pattern increases steadily from $\mathrm{R}^{2} \approx 0.29$ to 0.56 (space syntax, $2.5 \mathrm{D}$ ) and from $\mathrm{R}^{2} \approx 0.54$ to 0.72 as the 3D transport geography spatial model LOWand completeness increases. A novel hybrid angular-Euclidean analysis was tested for the objective description of 3D multi-level IO-ML$\mathrm{BE}$ route choice and wayfinding complexity. The results suggest that pedestrian route choice, wayfinding and movement pattern prediction research in a multi-Pevel lo-ML-BE should use high-definition 3D transport geography network spatial model and include interdependent outdoor and indoor spaces with detailed vertical transitions. volume 


\section{Introduction}

During walking navigation and wayfinding, cognitive spatial model of the Built Environment (BE), stored information, relative knowledge relation, and spatial feature attributes are continuously updated (Montello, 2005). Various spatial models and metrics Boeing, 2019; Coutrot, et al., 2020) are used, such as entropy, to objectively characterize BE spatial route choice complexity and wayfinding, linking objective measures of space to cognition and action (Zimring \& Dalton, 2003). This study focuses on network based objective spatial models and analyses of BE layout complexity used in 3D indoor and outdoor multi-level BE for pedestrian movement-pattern prediction, wayfinding and route choice studies.

Navigating across 3D large-scale IO-BE is a complex process involving both locomotion and wayfinding component (Millonig \& Schechtner, 2007). In such environments, people move between indoor and outdoor, through transitional space that can be below ground, at ground (e.g., atrium, arcade, shopping mall), and/or aboveground, in outdoor, or semi-outdoor covered walkway and skywalk. Categorizing such spaces requires anew classification (Yan, et al., 2019; 2021). Multi-level indoor often differ in structure, they are spattally more compressed, and how people perceive and move between different floors, use vertical mode of transition (lift, escalator, stair, ramp, and stairs) (Kondyli \& Bhatt, 2018) that are oftendesigned and integrated as landmarks. This is not usually the case for urban outdoor space. Landmarks in outdoor environment are different than those in indoor spaces. They contrast by the extent of the field of view, shorter indoor and longer outdoor. Outdoor also allow for the use of cardinal points or far away landscape features to orientate which mostly will be unavailable while indoor. Som outdoor space also combines lift, escalator, travelator, stair, ramp, stairs, and slope. example, in Hong Kong, the Central business district includes an entanglement of large scale vertical and horizontal traversable mixed-use buildings, at ground, above and below ground, indoor and outdoor, public and private realms including a succession of large atriums and a 
How 3D complex network volumetrics improve analysis

range of seamlessly functioning vertical transitions (Table ST1) also linked to mass-transit stations. The specificity of such intense public transport and pedestrian transport oriented developments is an emerging worldwide urban phenomenon called volumetric urbanism (Cui, et al., 2013; 2015; Cho, et al., 2015; Harris, 2015; Shelton, et al., 2011; McNeill, 2019; Yoos \& James, 2016; Mangin, et al., 2016). The complexity of these urban structures to a large part determines the complexity of wayfinding (Richter K, 2009) for millions of people daily. However, research still lacks appropriate 3D spatial model and analysis of such complex configurations (Hötscher, et al., 2013; Kuliga, et al., 2019; Vanclooster \& De Maeyer, 2012). In such settings, it is difficult to divide urban space into outdoor and indoor. As an experience, it is a continuous and variegated cognitive-visual-locomotive experience. Kondyli \& Bhatt (2018) argue that navigating routes within 3D large scale mixed indoor and outdoor environment is a significant challenge because such highly mixed structures are much larger than the sensorial horizon of a user with high potential for perception misalignment and distortions of spatial models which probably differ from the micro-scale focus of indoor research found in the evacuation management literature (Zhou, et al., 2015) or the limited scale of building wayfinding research (Hölscher, et al., 2013; Kuliga, etal., 2019) or the unmixed outdoor investigation (Hölscher, et al., 2011).

Navigation guidance aids system has been developing much faster for gutdoor than they have for indoor (Vanclooster \& De Maeyer, 2012) with key issues of lack of details, and routing algorithm, mostly using Euclidean shortest path routing. Thus, ignoring pedestrian route choice cognitive preference such as least turn (Vanclooster, et al., 2014), least angular/vector (Hiltien \& Iida, 2005; Bongiorno, et al., 2021) , or hybrid, i.e., most direct and shortest (Shatu, et 2019). Complex mixed BEs remain a challenge for GPS due to the complexity of accurate and seamless location positioning $(\mathrm{Xu}$, et al., 2020) across multi-level indoor and outdoor, and rich topography (Sun, et al., 2019). 
How 3D complex network volumetrics improve analysis

The recent availability of a unique large scale open data 3D indoor and outdoor pedestrian network (3DPN thereafter) (HKSAR LandsD, 2020) that has been integrated into a multimodal navigation app (HKSAR BD, 2020) using the shortest Euclidean routing and associated with a range of 3D Models (HKSAR PlanD, 2018) and topographic map makes possible to contribute to the literature by:

proposing and implementing several 3D analytical and visualization techniques to support the spatial cognitive complexity analysis of an implemented 3D indoor and outdoor multilevel navigation pedestrian network (3DPN).

- testing empirically whether a 3D angular complexity analysis can predict pedestrian volume patterns in the 3DPN. To date, 3D turn (topological distance), and angular (least angular change(vector) analysis have not been used to account for large-scale 3DPN spatial cognitive volumetric-complexity.

- testing a hybrid metric (Euclidean + angular), i.e., shortest, and most direct (least angular change).

- testing an enhanced version of the 3DPN by increasing indoor pedestrian network LOD.

- comparing with network-based 2.5 topological analysis (Kee, 2004; Dao \& Thill, 2018) and specifically space syntax spatial model, 2.5D axiallime network, axial segment (Chang \& Penn, 1998; Hillier \& Iida, 2005) that emulate the 3DPN, to investigate whether such spatial model is necessary for automatically and meaningfully calculate turn and angular complexity and their impact on associatto with movement pattern, route choice and wayfinding studies.

- Test empirically "inherent intelligibility" as predictability indicator (Penn, 2003, p. 37 \& 45) which has been shown to be morphologically inconsistent (Zhang, et al., 2013). 


\section{Review of Relevant Studies}

Space syntax is a 2D network-based configurational analysis of building and urban morphology complexity (Rashid, 2019). There are three prevailing motivations for using space syntax to analyse the impact of BE spatial structure complexity on movement pattern, navigation and wayfinding (Penn, 2003; Hillier, 1999; Zimring \& Dalton, 2003; Hölscher, et al., 2012; Kuliga, et al.. 2019; Carlson, et al., 2010):

1. Spatial linear model: the axial line and its spatial disaggregation/derivation into segment spatial model representing line of sight/movement, from which quantitative layout complexity measures such as topological 2Dyand 2.5D analysis are derived (Bafna, 2003; Haq \& Zimring, 2003; Kuliga, et al., 2019) The more recent segment map and software enables angular (least angular distance between ongin and destination) and Euclidean (shortest path) analysis (Hillier \& Iida, 2005).

2. From the linear spatial model, 2D quantitative configurational analyses of the spatial model have high association with the aggregate movement rates of pedestrians and vehicles, route choice and wayfinding decisions, and wayfinders' understanding of the spatial environment (Kuliga, et al., 2019), with unexplained variances often being associated mith individual differences (Penn, 2003).

3. An "inherent intelligibility" indicator based on axial line spatial model, as a "local are effect". The high/low measure of the "inherent intelligibility" (Penn, 2003, p. 37 \& 45; Li \& Klippel, 2016) of a spatial configuration is used as a predictor/explanation of the strong/weak association of space syntax analysis with movement rates in intelligible/"unintelligible", 2D, and 3D BE (Chang \& Penn, 1998; Penn, 2003). 
How 3D complex network volumetrics improve analysis

For a recent, extensive review and contextualization of the concepts, methods, and analyses of space syntax, see Rashid (2019) and Oliveira (2016).

\section{Spatial linear model - axial line, segment line, and evolution to 3D}

p. 91) Wt was developed to describe and characterize buildings and settlements and enable the explicit measurement of spatial configuration simplicity/complexity (Hillier, 1996; Hanson, 1998). Axial line spatral models have been used to model street layouts, 2D outdoor BEs, 2D pedestrian paths, and 2.5D multi-level indoor buildings (Chang \& Penn, 1998; Hölscher, et al., 2006; 2011; 2012). Early criticism of this spatial model (Jiang \& Claramunt, 2002; Ratti, 2004; Salheen \& Forsyth, 2001) pointed out the relatively subjective nature of the encoding process, solution (Batty, 2004; Turner, et ar., 2005), the lack of geometric, scale, and Euclidean considerations, the aggregated nature of the spatial model, the two-dimensionality (Pafka, et al., 2020), and the under-determination of the axialline as the "line of sight" and/or line of movement (Marshall, 2005, p. 115; Pafka, et al., 2020).

\section{Geometry, scale, and metrical considerations, line of movenent, Tine of sight}

At the core of layout, complexity measurement is the idea that the BE can be understood as a network of interconnected units. Complexity, initially conceptualized as at topological property of axial line and how axial line as spatial units of analysis are interconnected to each other, has evolved with the segment map, angular analysis, and Euclidean radius creating geometric relationship with Euclidean metric conditioning in $2 \mathrm{D}$ and $2.5 \mathrm{D}$. The combination of the segment map as a street spatial model and the use of angular analytics and Euclidean radius has shown a higher level of association with pedestrian and vehicular flow (Hillier \& Iida, 2005; Hillier, 2012). Axial and segment spatial models have been equally used (Sharmin \& 
How 3D complex network volumetrics improve analysis

Kamruzzaman, 2018). A first hypothesis (H1) is that, given an operationalizable 3D spatial model, the Euclidean conditioned angular analysis can be extended to 3D although with a remaining under-determination of Euclidean properties.

The connectivity and continuity of the line of movement are entangled with sight, spatial cognition, and wayfinding heuristics but this does not necessarily equate "axial line" with line sight (Marshall, 2005; Figueiredo \& Amorim, 2005). It is hypothesized (H2) as suggested by (Chang \&Penn, 1998) and Turner (2007) that the centreline, the line of movement, is a valid spatial model/generalization of line of sight for pedestrian.

\section{Spatial aggregated nature of the axial/segment line spatial model of pedestrian path \\ Desyllas and Duxbury (2001), noting different pedestrian flow patterns on two sides of the} street, proposed encoding the two sides of the street and crossings as opposed to aggregated encodings, such as axial lines or segment encoding, that generalize the pedestrian paths of the two sides of street into one single line. Visual Graph Analysis (VGA) (Desyllas, et al., 2003; Turner, et al., 2001) was shown to be effective systematically capturing two sides of the street, pedestrian crossing configurations, and showing high association with pedestrian flow. However, empirical VGA and two-sided pedestrian network studies are scarce. A hypothesis (H3) is to extend the principle of the road centreline 2D spatial model to detailed pedestrian path encoding. This is extending to pedestrian network, the standard road centreline network linear referencing system used in transport geography (Figure S01:a), and in transport (Garrison \& Marble, 1962; Haggett \& Chorley, 1969; ISO, 2011; FHWA, 2014; Marshall, 2016; Marshall, et al., 2018). These spatial models differ from that used by Turner (2007)which decompose a curve into series of short straight segments (Figure S02:b), instead, the curved link between two junctions is one spatial unit (Figure S01:a). Angular analysis is operationalized as angular change along a medial/centre line path, calculated cumulatively along straight and curve links and through junctions (Cooper \& Chiaradia, 2020). 
The encoding principle follows a medial/centre path of the pedestrian network on both sides of the street and the crossings (Figure S01:b). This principle also follows pedestrian path encoding, not implemented in space syntax, proposed by Chang and Penn (1998, p. 525) (Figure S03). Extending this encoding principle from indoor to outdoor should overcome the inconsistencies arising with VGA (Ericson, et al., 2020; Zhang, et al., 2013) and the criticism of axial

\section{From 2D $2.5 \mathrm{D}$ the axial/segment line to 3D}

Chang and penn (1998) and others (Kuliga, et al., 2019; Chang, 2002; Lu \& Ye, 2017; Hölscher, et al., 2006, 2012) have highlighted the important role of vertical transition in navigation. There are calls for better encoding of vertical transition configurations to better understand their roles in multi-level navigation and wayfinding (Hölscher, et al., 2013; Lu \& Ye, 2017; Montello, 2007). Two strands of space syntax extensions to 3D have been proposed, a network and an isovist/visual graph approach(See Table ST2 for a summary). The 3D space syntax extensions have been recently reviewed(Rashid, 2019). These 3D space syntax extensions, for example, quantify urban visibility using 3D axial lines and height changes. None of these extensions have been empirically tested and operationalized in movement patterns or wayfinding analysis.

Indoor and outdoor multi-level pedestrian movement, route choiee and yayfinding studies (Kuliga, et al., 2019; Chang \& Penn, 1998; Hölscher, et al., 2012) using space sygtax resort to an oversimplified linear spatial model of vertical transition configurations flattened on a plane, using an additional axial line to encode connection between floors. This is a $2.5 \mathrm{D}$ spatialmodet, The 2.5D limitation makes it extremely difficult to operationalize this spatial model for mult level urban area that combines indoor and outdoor publicly accessible paths, such as in Chang and Penn (1998) where key publicly accessible indoor floors were omitted. We hypothesize 
(H4) that these omissions impact negatively on movement patterns, route choice and wayfinding analysis.

In spatial cognition and wayfinding studies, several aspects are contested such as whether cognitive maps are mainly 2D, or 3D (Kim, et al., 2017), whether or not users expect identical floor layouts in multi-level buildings (Carlson, et al., 2010; Hölscher, et al., 2006; 2012). Lu and $\mathrm{Ye}$ wayfinding study (2017), in agreement with Berthoz \& Thibault (2013; Thibault, et al., 2013), suggested that in multi-level buildings, people can integrate volumetric cognitive map and that the previous findings might be limited by the specific wayfinding task protocol used. To contribute to this debate meaningfully (Hinterecker, et al., 2018; Grieves, et al., 2020), the 2D hybrid spatial/model (Figure S01: c \& d) proposed by Cooper et al. (2019) is implemented in 3D to encode topography, lift, stairway, ramp, or escalator, combining horizontal and vertical curvilinearity as shown in Figure 1 (Cooper \& Chiaradia, 2020). These $3 \mathrm{D}$ encoding principles are major changes from the space syntax 2.5D linear network-based configurational approach to a complex 3D multi-level IO-ML-BE spatial structure. This 3D spatial model provides objective measures of body rotation between floors and level of correspondence floor by floor and across floors. All nodes are also decision points which is not the case in Turner (2007) (See S02a), which can adversely impact route choice and wayfinding research. 


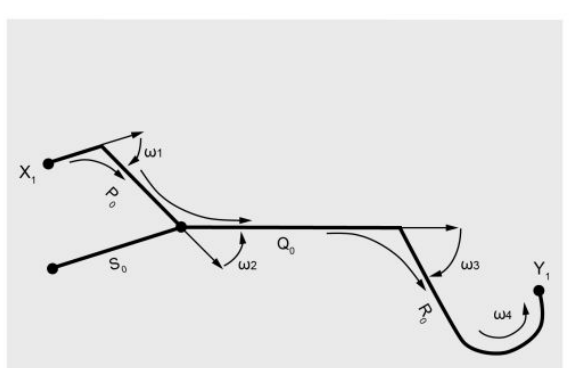
$\frac{L^{Y}}{x}$
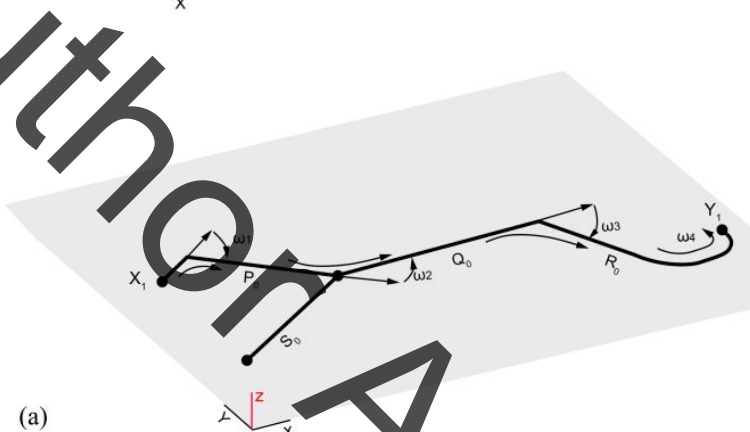

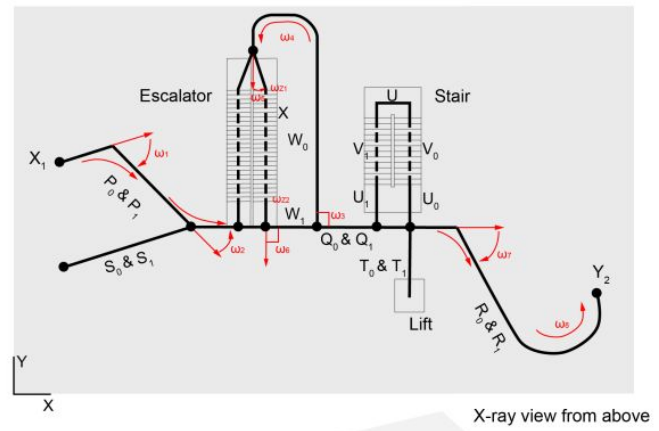

(b)

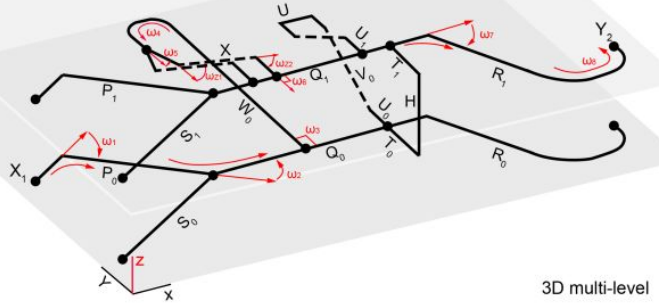

Figure 1. Pedestrian network encoding in 2D vs 3D: a. 2D road centerline encoding and angular analysis principle (Turner, 2007) and b 3D medial center path encoding and 3D angular analysis principle (Cooper \& Chiaradia, 2020).

\section{Associations with pedestrian movement, cycling, and vehicular movement patterns}

The strong association with aggregate observed pedestrian and vehicular movement distribution is a key motivation for route choice and wayfinding studies to use space syntax (Penn, 2003; Kuliga, et al., 2019; Farr, et al., 2012)

The strong associations (60 to $80 \%$ of the variandes) between layout configuration complexity analysis and aggregate movement patterns provide no direct understanding of individual cognitive processes, route choice and wayfinding. It is thegrized that spatial cognition and navigational expertise, whether as walking, cycling or driving, elicit the deployment of cognitive processes, route choice and wayfinding heuristics that are also dependent on layout complexity (Woollett \& Maguire, 2011; Penn, 2003; Hölscher, et 21.2012 Hillier \& Iida, 2005). We hypothesize (H5) that the same configurational analysis using a different 2D spatial model, presenting similar strong associations with movement rates, is a plausible candidate to objectively describe BE complexity for wayfinding studies (Kang, 2017; Cooper \& Chiaradia, 2015; Cooper, 2017; 2018; Wedderburn \& Chiaradia, 2014; Jayasinghe, 
How 3D complex network volumetrics improve analysis

et al., 2019). Cooper et al. (2019), in the first longitudinal study, showed that the use of the proposed spatial model enables predictive pedestrian movement after a major configuration change in a city centre.

\section{"Inherent" intelligibility/unintelligibility vs individual and cultural adaptation?}

more specifieally, from moving around from one part to another", i.e., inferences beyond visual local cues. Intelligibility/unintelligibility are operationalized as an index, the highassociation/low-assocration between local measure of Connectivity/Degree of axial line and Integration/Closeness of the whole system. The concept of "inherent intelligibility/unintelligibility" and their relation to wayfinding ease is a widespread area of interest in the literature (Penn, 2003; Dalton, et al., 2015; Haq, 2003). Legibility of an environment (Lynch, 1960; Weisman, 1981) the ease with which an urban structure can be comprehended and intelligibility have been shovn to be related (Long \& Baran, 2012). A metric of legibility includes the connectivity metric of layout, as interconnection density (O'Neill, 1991) which is fraught with the Modifiable Area Unit Problem (MAUP). High/low intelligibility is used as a predictor of the (high/low) association between space syntax spatial complexity analysis and pedestrian movement patterns and wayfinding task difficulty (Penn, 2003). Chang and Penn (1998) analysed 3D multi-level configurations that were found unintelligible thus explaining the poor association between pedestrian movement patterns and space syntax axial line analysis. However, despite formal confounding issues operationalization of an intelligibility index (Zhang, et al., 2013; Long \& Baran, 2012) appears that the spatial model and analysis used play an unaccounted major role in the level of association with the pedestrian movement pattern. Hillier and Iida (2005) show that the changes from axial line to the derived segment line spatial model and from topological to angular 
How 3D complex network volumetrics improve analysis

analyses vary the association with the pedestrian movement rate from $-13 \%$ to $+54 \%$ without change of configuration, or in the "inherent intelligibility" index. These variations cast doubts on the robustness and reliability of space syntax's "inherent intelligibility" index.

The large-scale navigability ability study of Coutrot et al. (2020) indicates that cognitive abilities for spatial navigation are clustered globally according to economic wealth and gender. Also, $g$ wing up in a city with a "complex" layout positively impacts navigational skills. These studies suggest that intelligibility will vary not only with inter-individual but also with crosscultural differences. These findings further problematize the construct of "inherent intelligibility" (Penn, 2003) and suggest both individual and dynamic cultural unaccounted variations. Thus, an "unntelligible" layout in London might be nevertheless intelligible elsewhere.

In summary, this study hypothesizes that by using 3D transport geography, path centre line for pedestrian spatial model with higher IOD and completeness, using the association with pedestrian movement patterns as control, we would find a higher association in large-scale IOML-BE, see supplementary materials for complete detail

Datasets and Methods

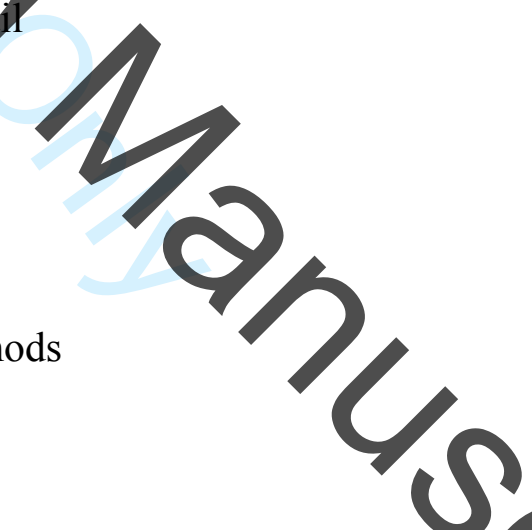

\section{Case study selection}

As Chang and Penn (1998), use the exceptional South Bank and Barbican as critical case studies in London, similarly, we implement a critical case selection and research strateg (Flyvbjerg, 2001). The case is selected on the base of expected content (See S04): exceptional study area with inherent intelligibility close to zero, as in Chang and Penn, using the same spatial modelling, the axial line and other spatial model, we are expecting low predictability of pedestrian flow patterns. By showing that the predictability of pedestrian flow 
How 3D complex network volumetrics improve analysis

is high would permit us to conclude that if "inherent" intelligibility/unintelligibility" is not valid for this case, then it applies to all the cases (Flyvbjerg, 2001, p. 79).

\section{The Study Area}

With over 7.4 million people and a built-up land area covering approximately $25 \%$ of its territory, Hong Kong has one of the highest population densities in the world. Walking is the main way of moving between public transport modes which has $90 \%$ transport modes share. Hong Kong has adapted walking to a typhoon-prone, sub-tropical climate, and the city's rich topography. It has evolved into a complex volumetric mode of development (Shelton, et al., 2011), broadly defined as integrating multiple modes of transport with vertically stacked mixeduse, and integrated horizontally through walking below, at ground, and above ground, combining outdoors and indoors, and mingling public, quasi-public, and private ownerships that are publicly accessible and seanless. These configurations often result in segregation between pedestrian and motorized vehicle. Shch arban development can be found in other cities around mass-transit urban rail stations (Yoos \& James, 2016; Mangin, et al., 2016; Samant, 2019; Chang \& Penn, 1998).

The study area is defined as an $800 \mathrm{~m}$ catchment area $(2.2 \times 1.6 \mathrm{~km})$ from the entrances/exits of two linked mass-transit stations: Central and Hong Kong. It excludes the inner-urban rail station's paying area. Workplace density ranges from 1,140 to $2,990 \mathrm{jobs} / \mathrm{ha}$, while the residential density range from 12 to 465 person/ha. These differentiated ranges, between jobs and resident, are a typical morphological signature of Central Business District and implies that most users are familiar with the IO-ML-BE configuration. The study area also attracts many tourists who might mostly be first-time visitors. The overall area and the study area have "inherent intelligibility" that are very low (S05).

\section{D Pedestrian network - study area}


The 3D indoor and outdoor multi-level pedestrian network (3DPN) is extracted from the open data set provided by HKSAR LandsD (2020). An overview of the data model is provided in S06. The 3DPN spatial model follows Figure $1 \mathrm{~b}$ principles.

In the study area, the multi-level outdoor covered walkway network is $7.8 \mathrm{~km}$ long. It was deyeloped piecemeal by various private developers and the Hong Kong Government since the 1970s (Ian \& Xue, 2014). This 3D multi-level pedestrian network extends horizontally indoor connecting via multiple access to 70 traversable buildings as a combination of undergroundground, or ground and above ground or underground-ground and above ground. The 3DPN plays an essential role in connecting dense, multi-level, publicly accessible mixed-use areas (Figure S07). This very complex urban environment has attracted various descriptive studies (Frampton, et al., 2012; Xue, 2016; Sun, et al., 2019; Zhao, et al., 2020).

\section{Pedestrian Data Collection}

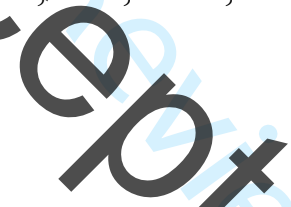

Pedestrian movement pattern data was gathered in the Central area as a dependent variable and used as a quantitative control test for the analysis of objective IO-ML-BE spatial models analyses as independent variables. The 'Cordon Count' method of observation was used for gathering pedestrian volume data (S08). Table ST3 shows the descriptive statistics for all 33 observed cordon counts and Figure S08:a shows the cordon count location. Figure S08:b presents the associations between all-day average flow rates and each period the average of six time periods throughout the day is a good representation of each period. Whe also yaried the pedestrian survey methods using one weekday video survey and 3 days video survey to further ascertain the robustness of the findings. The results hold, see details in S08 and S09.

\section{Pedestrian Network Spatial Models}

In this study, a standard-mixed axial line spatial model and four spatial models are compared with different levels of 3D definition and completeness. The 3DPN has a simplified pedestrian 
How 3D complex network volumetrics improve analysis

indoor network (PIN) which is used to make spatial models comparable, yielding nine spatial models. Detailed descriptions are given in the S11 with a graphic summary. For the standardmixed axial line spatial model see Chang and Penn (1998) and S10.

Table ST4 compares the descriptive statistics of the axial, segment, 3D outdoor path-centre line, and complete 3D indoor-outdoor path-centre line maps. 2012). this study: closeness and betweenness centrality (Hillier \& Iida, 2005; Cooper \& Chiaradia, 2020). In space syntax software, closeness centrality is called 'integration' or 'mean depth', and betweenness centrality is called choice' (Hillier \& Hanson, 1984).

Axial and segment maps are processed with open source DepthmapX software (Varoudis,

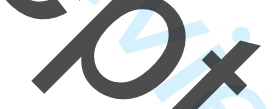

Path-centre line 3D maps are analysed with the open-source 3D sDNA software toolbox (Cooper \& Chiaradia, 2020; Chiaradia, et al., 2014). Figure S12 shows how a subset of the spatial model defined by a reach radius based on 3D network (Cooper \& Chiaradia, 2020).

Radius, according to the Travel Characteristics Survey 2011 (Transport Department, 2014), over $75 \%$ of Hong Kong residents walked up to 5 minutes, about $400 \mathrm{~m}$, from their trip origin to access either a mechanized transport mode or their trip destination. For axial maps, choice and integration are calculated with radii from R3 to R10 as comparable. Similarly, for segment maps, choice and integration are calculated for every $100 \mathrm{~m}$ radius within the walking distance range of 200 to $800 \mathrm{~m}$.

\section{Hybrid Distance Metric}

sDNA as DepthmapX software operationalises analytical metrics such as angular (most direct path), Euclidean (shortest path), and topological (least turn path). sDNA provides a novel 
How 3D complex network volumetrics improve analysis

'hybrid' metric (shortest and most direct). In a recent study, Bongiorno, et al. (2021) reported that pedestrians between Origin-Destination tend to minimize the horizontal directional changes (least angular/vector) and Shatu et al. (2019) reported path length reduction where possible: $28 \%$ of the chosen routes satisfied both shortest distance and most direct criteria. Berthoz et al. (1999) indicated that distance and direction might be encoded separately in human cognition yet interacting (Zhang, et al., 2015). sDNA allows the mixing of both the shortest and least angular/yector changes in one metric to explore relative interaction. The hybrid distance metric is defined along the link in Equation (1) and for the junction in Equation (1).

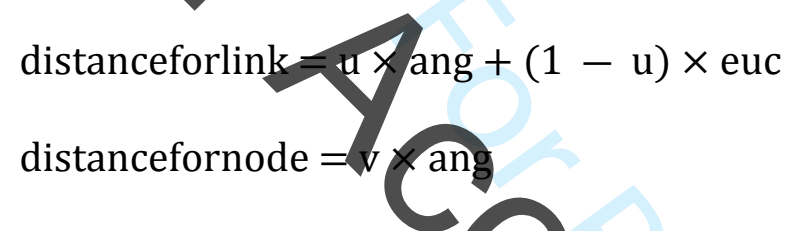

The weighting constant $u$ and $w$ specifies the relative importance of angular distance over Euclidean distance, where $u=1$ represents pure angular, and $u=0$ represents pure Euclidean. ang is the cumulative angular change along a link or angular change at junction. We tested the hybrid metric by varying the Angular/Euclidean ratio to investigate different weighting: a1:e0 (pure angular), a1:e2, a1:e1, a2:e1, a0:e1 (pure Euclidean).

Results

To test the relationship between spatial models at different radinand observed average daily pedestrian movement, a bivariate regression analysis was adopted for al the spatial models. The highest R-square values between pedestrian movement pattern distribution and centrality measures are shown in Table ST5 and all results are shown in S13.

The results show that:

1. The measure of layout complexity's association with pedestrian movement patternin volumetric $\mathrm{BE}$ is significantly affected by the choice of pedestrian network spatial model (2.5D space syntax vs 3D transport geography) and its LOD and completeness. (See S14 for detailed descriptions). 
How 3D complex network volumetrics improve analysis

2. Coefficient of determinations increase steadily from $\mathrm{R}^{2} \approx 0.29$ to 0.56 (space syntax, $2.5 \mathrm{D})$ and from $\mathrm{R}^{2} \approx 0.54$ to 0.72 for the $3 \mathrm{D}$ transport geography spatial model as LOD and completeness increases to high level (Table ST5).

3. To test the impact of the pedestrian survey method, a video survey with $\mathrm{N}=293,625$ was used and gives similar results (S09).

4 To test the strength of the findings, a multivariate stepwise regression analysis was ecuted with independent variables such as volumetric density; diversity as shopping mall egress; design such as pathway width, network density within 400m, junction density, footbridge; distance to transit such as closest mass-transit egress (S15). Table ST6 shows thatDistance to transit egress and hybrid closeness enter the model with an adjusted $\mathrm{R}^{2} \approx 0.78$.

5. Table 1 shows the strong cross-associations among four 3D metrics of betweenness measures for the complete 3D indoor \& outdoor, 2 side path-centre line spatial models. The results demonstrate that the hybrid metric that combines angular and Euclidean, enables a better understanding of the interactions between shortest paths and least angular/vector paths.

Table 1. R-square coefficients between betweenness measures of $3 \mathrm{D}$ indoor-outdoor pedestrian network (Radius at $500 \mathrm{~m}, \mathbf{N = 3 3}$ ).

\begin{tabular}{cllll}
\hline & Angular & Euclidean & Topologic \\
\hline Angular & 1 & & \\
Euclidean & $\mathbf{0 . 8 3 4}$ & 1 & \\
Topologic & $0.570^{* *}$ & $0.694^{* *}$ & 1 \\
Hybrid (1:) & $\mathbf{0 . 8 7 7 ^ { * * }}$ & $\mathbf{0 . 9 8 9}^{* *}$ & $0.597^{* *}$ & 1 \\
\hline ** $\leq 0.01$ level. & \\
Discussion and Conclusion
\end{tabular}

In this study, we show for the first time how 3D least angular change centrality analysis, as an objective measure of pedestrian layout complexity and index of route choice and wayfinding 
difficulty (Carlson, et al., 2010), can be innovatively and effectively deployed in 3D (H1). This is achieved by using a 3D transport geography spatial model (H2 \& H5) that extend the principles of the $2 \mathrm{D}$ road centreline spatial model to 3D disaggregated two sides of the street and crossing pedestrian path encoding (H3) with network-based geometric details of vertical transitions, and this in a topographically rich study area with extensive complex multi-level ouddoor and indoor pedestrian paths, i.e., in volumetric urbanism (Shelton, et al., 2011; McNeil, 2019).

The key innovation is that a link, as a spatial unit of analysis between two junctions (Figure 1), combines horizontal and vertical curvilinearity to account for vertical transition, making the spatial model truly $3 \mathrm{D}$. The results also show that the omission of interdependent indoor publicly accessibly multi-level pedestrian paths impacts negatively on association with movement patterns (H4), by almost halving the level of association (Table ST5).

The 3D transport geography spatial models and their analysis still stress the importance of configuration, geometry, Euclidean distance and enable the measure of complexity, degree of correspondence, direct measure of rotation or overlap between floor-to-floor plans (Carlson, et al., 2010; Kondyli \& Bhatt, 2018). The operationalisation of a novel closeness and betweenness 3D hybrid analysis, combining the 3D angular and Euclidean, conditioned by the 3D Euclidean radius, shows promising results that corroborate existing route choices studies (Shatu, et al., 2019; Bongiorno, et al., 2021). Our findings align with previous studies that hay shown how spatial model can greatly impacts results (Hillier \& Iida, 2005; Turner, 2007; Zandbergen, et al., 2011; Chrisman, 1991; Fotheringham \& Wong, 1991).

In empirical studies of Barbican and South Bank in London, Chang and Penn (1998) attributed negligible associations between the logarithm of pedestrian movement rates and integration values to the weak association between local and global measures, or the lack of “inherent intelligibility" of the BE. In Hong Kong, Central, despite null "inherent intelligibility" 
How 3D complex network volumetrics improve analysis

(S05), the space syntax 2.5D spatial models' association with pedestrian movement pattern were moderately high in contrast to very low in a previous study in London (Chang \& Penn, 1998). All the spatial models' predictability ranges from moderately high for space syntax (2.5D), to high for 3D transport geography spatial model with high LOD. The predictability of a system is not related to its "inherent intelligibility", thus not only "inherent intelligibility" has formal is

Given the high level of 3D complexity of the study area and the high association with movement patterns, following the findings of Coutrot et al. (2020) we may conjecture of a local spatial culture effect which problematize direct comparison and/or "best practice" direct import between different spatial cognition cultures. In that sense, the comparison of pedestrian patterns in New York, Manhattan, and Hong Kong, because they have similar densities is not warranted given their spatial cognition culture differences: flat regular grid vs topography rich, deformed grid and multi-level confound route choice study (Guo \& Loo, 2013), Euclidean distance only based walkability scoring and accessibility assessment (Zhao, et al., 2020; Tang, et al., 2021). The globalisation of designers, researchers and policymakers accustomed to liberal borrowing need to be challenged and require better understanding of the jnterphay of individual difference and the evolving plasticity or not of spatial cognition culture(s)

Volumetric urbanism, transport-oriented development, and large-scale 3D IO-ML-BE create new cognitive, wayfinding, urban planning, and design challenges due to their spatpal scale, and their outdoor-indoor heterogeneity and complexity. These complexities can increase from incremental additive development over time, such as in Central, Hong Kong, or in "allatonce" design, for example in Sha Tin, Hong Kong, or the Barbican in London. This study's results suggest that large-scale complex IO-ML-BE design can be analysed and informed by 3D analysis using 3D transport geography spatial model. Such spatial models also support the inclusion of a wide varieties of attributes to characterise what is along of beside the walking 
How 3D complex network volumetrics improve analysis

path. They also enable linear referencing of semantic attributes along movement lines or other $\mathrm{BE}$ attributes in $3 \mathrm{D}$.

There are several limitations to this study. It is a single extreme layout complexity case study research design, meaning that traditionally its findings may not have high external validity. Yet, Flyybjerg (2001) argues that extreme case, such as Central in Hong Kong in term of spatial configurati

being measured, the layout complexity and predictability, and thus can be presented to capture the extreme extent of the diversity that can be observed in the reference class distribution. The concept of the "inherent" intelligibility" of a BE needs to be reconsidered when the spatial model itself impacts somuch on the results

Also, only weekday pedestrian volumes were examined, so an extension of this study would be to compare weekday and weekend pedestrian movement patterns. There is also no pedestrian flow measurement "strictly indoor" due to priyate ownership that would have been beneficial to include if available. Further investigation is a1soneeded to better understand the overlapping relationship between the 3D shortest angular path and the 3D shortest Euclidean path in a complex 3D BE, using 3D hybrid metrics, the variation of closeness and betweenness and area sampling effects. Moreover, further work could be conducted within Carlson et al.'s integrative framework (2010). Neuroscience perspectives provide salient BE features and configurations that could be tested to better inform spatial design legibility-intelligibility (Jeffery, 2019) with the inclusion of indoor-outdoor scene relationship. Given the plasticity of the spatial cognitive processes and the varieties of individual wayfinding capacities and strategies deployed, future research on the dynamics of individual and cultural cognitive differences that interplay with life-long change should be conducted to improve the understanding of the relationship between BE design, user characteristics, lifetime change and spatial culture change. 
How 3D complex network volumetrics improve analysis

\section{References}

Bafna, S., 2003. Space syntax: A brief introduction to its logic and analytical techniques. Environment and behavior, 35(1), pp. 17-29..

Batty, M. S., 2004. The automatic definition and generation of axial lines and axial maps. Environment and Planning B: Planning and Design, 31(4), pp. 615-640.

Berthoz, A. et al., 1999. Dissociation between distance and direction during locomotor navigation. In: G. Golledge, ed. Wayfinding behavior: Cognitive mapping and other spatial processes. Baltimore: John Hopkins University Press, pp. 328-348.

Bertho2, A. \& Thibault, G., 2013. Learning landmarks and routes in multi-floored buildings. Behavioral and Brair Sciences, 36(5), p. 545.

Boeing, G., 2019. Urban spatial order: Street network orientation, configuration, and entropy. Applied Network Science, 4(1), pp. 1-19.

Bongiorno, C. et al., 2021. Vector-based Pedestrian Navigation in Cities.

Carlson, L., Hölscher, C., Shipley, T.F. \& Dalton, R., 2010. Getting lost in buildings. Current Directions in Psychological Science, 19(5), pp. 284-289.

Chang, D., 2002. Spatial choice and preference in multilevel movement networks. Environment and Behavior, 34(5), pp. 582-615.

Chang, D. \& Penn, A., 1998. Integrated multifevel circulation in dense urban areas: the effect of multiple interacting constraints on the use of complex urban areas. Environment and Planning B: Planning and Design, 25(4), pp. 507-538.

Chiaradia, A., Crispin, C. \& Webster, C., 2014. sDNA a software for 3D spatial design network analysis. [Online]

Available at: www.cardiff.ac.uk/sdna/ [Accessed 15 June 2014].

Cho, I., Trivic, Z. \& Nasution, I., 2015. Towards an integrated urban space frameworkfor emerging urban conditions in a high-density context. Journal of Urban Design, 20(2), pp. 147-168

Chrisman, N. R., 1991. The error component in spatial data. Geographical information systems, 1(12), pp. 165-174.

Cooper, C., 2017. Using spatial network analysis to model pedal cycle flows, risk and mode choie Journal of transport geography, Volume 58, pp. 157-165.

Cooper, C., 2018. Predictive spatial network analysis for high-resolution transport modeling, applied to cyclist flows, mode choice, and targeting investment. International journal of sustainable transportation, 12(10), pp. 714-724. 
How 3D complex network volumetrics improve analysis

Cooper, C. \& Chiaradia, A., 2015. sDNA: how and why we reinvented spatial network analysis for health, economics and active mode of transport. Leeds, Leeds University - Figshare, pp. 122-127.

Cooper, C., Harvey, I., Orford, S. \& Chiaradia A, J., 2019. Using multiple hybrid spatial design network analysis to predict longitudinal effect of a major city centre redevelopment on pedestrian flows. Transportation.

Cooper, C. H. V. \& Chiaradia, A. J. F., 2020. sDNA: 3d Spatial Network Analysis for GIS, CAD, Command Line \& Python. SoftwareX, pp. 1-24.

Coutrot, A. et al., 2020. Cities have a negative impact on navigation ability: evidence from 38 countries. bioRxiv, pp. 1-13.

Cui, J., Allan, A.\& Lin, D., 2013. The development of grade separation pedestrian system: A review. Tunnelling and underground space technology, Volume 38, pp. 151-160.

Cui, J., Allan, A. \& Lin D, 2015. Assessing grade separation pedestrian systems: Planning, design and operation. Urban designinternational, 20(3), pp. 241-252.

Dalton, R., Hoelscher, C. \& Spiers, H., 2015. Navigating complex buildings: Cognition, neuroscience and architectural design. In: J. Gero, ed. Studying visual and spatial reasoning for design creativity. Dordrecht: Springer, pp. 3-22.

Dao, T. \& Thill, J., 2018. Three-dimensional indoor network accessibility auditing for floor plan design. Transactions in GIS, 22(1), pp. 288-310

Desyllas, J., Connoly, P. \& Hebbert, F., 2003. Modelling natural surveillance. Environment and Planning B: Planning and Design, 30(5), pp. 643-655.

Desyllas, J. \& Duxbury, E., 2001. Axial maps and visibility graph ahalysis. Atlanta, Georgia Institute of Technology, pp. 27.1-27.13.

Ericson, J., Chrastil, E. \& Warren, W., 2020. Space syntax visibility graphanalysis is not robust to changes in spatial and temporal resolution. Environment and Planning B.UrbanAnalytics and City Science, pp. 1-17.

Farr, A., Kleinschmidt, T., Yarlagadda, P. \& Mengersen, K., 2012. Wayfinding: A simple concept, a complex process. Transport Reviews, 32(6), pp. 715-743.

FHWA, 2014. All Road Network of Linear Referenced Data (ARNOLD) Reference Manual. Washington, D.C.: US Federal Highway Administration (FHWA).

Figueiredo, L. \& Amorim, L., 2005. Continuity lines in the axial system". In: van Nes, A. (ed.), Proceedings of the. In: A. van Nes, ed. Proceedings of the 5th International Symposium on Space Syntax. Delft: Delft University of Technology, pp. 161-174 (1).

Flyvbjerg, B., 2001. Making social science matter: Why social inquiry fails and how it can succeed again. Cambridge: Cambridge University Press. 
How 3D complex network volumetrics improve analysis

Fotheringham, A. S. \& Wong, D. W., 1991. The modifiable areal unit problem in multivariate statistical analysis. Environment and planning A, 23(7), pp. 1025-1044.

Frampton, A., Salomon D, J. \& Wong, C., 2012. Cities Without Ground, A Hong Kong Guidebook. New York: Oro Editions.

Garrison, W. L. \& Marble, D. F., 1962. The Structure of Transportation Networks. Evanston, IL: Transportation Center Northwestern University)..

Grieves, R. et al., 2020. The place-cell representation of volumetric space in rats. Nature Communications, 11(1), pp. 1-13.

Guo, 2. \& Loo, B. P., 2013. Pedestrian environment and route choice: evidence from New York City and Hong Kong. Journal of transport geography, Volume 28, pp. 124-136.

Haggett, P.\& Chorley, R. J., 1969. Network Analysis in Geography. London(UK): Hodder \& Stoughton Educational.
Hanson, J., 1998. Decoding Homes and Houses. Cambridge: Cambridge University Press.

Haq, S., 2003. Investigating the syntax line: configurational properties and cognitive correlates..

Environment and Planning B: Planning and Design, 30(6), pp. 841-863.

Haq, S. \& Zimring, C., 2003. Just down the road a piece: The development of topological knowledge of building layouts. Environment and behavior, 35(1), pp. 132-160.

Harris, A., 2015. Vertical urbanisms: Opening upgeographies of the three-dimensional city. Progress in Human Geography, 39(5), pp. 601-620

Hillier, B., 1996. Space is the machine: A configurational theory of architecture. Cambridge: Cambridge University Press.

Hillier, B., 1999. The hidden geometry of deformed grids: or, why space syntax works, when it looks as though it shouldn't. Environment and Planning B: planning and Design, 26(2), pp. 169-191.

Hillier, B., 2012. Studying cities to learn about minds: some possible implications of space syntax for spatial cognition. Environment and Planning B: Planning and Design, 39(1), pp. $12 \div 32$.

Hillier, B. \& Hanson, J., 1984. The Social Logic of Space. Cambridge: Cambridge University Press.

Hillier, B. \& lida, S., 2005. Network effects and psychological effects: a theory of urban movement. In: G. Cohn A \& M. Mark D, eds. Spatial Information Theory. COSIT 2005. Lecture Notes in Computer, Science, vol 3693. Berlin, Heidelberg: Springer, pp. 475-490.

Hinterecker, T. et al., 2018. No advantage for remembering horizontal over vertical spatial locations learned from a single viewpoint. Memory \& cognition, 46(1), pp. 158-171.

HKSAR BD, 2020. Building Records Access and Viewing On Line. [Online]

Available at: https://bravo.bd.gov.hk/login.action

[Accessed 06 2019].

HKSAR LandsD, 2020. 3D Pedestrian Network, Hong Kong: HKSAR. 
How 3D complex network volumetrics improve analysis

HKSAR PlanD, 2018. 3D Phto realistic model. [Online]

Available at: https://www.pland.gov.hk/pland en/info serv/3D models/download.htm

[Accessed 2020].

Hölscher, C., Brösamle, M. \& Vrachliotis, G., 2012. Challenges in multilevel wayfinding: A case study with the space syntax technique. Environment and Planning B: Planning and Design, 39(1), pp. 63-82.

Hölscher, C., Büchner, S. \& Strube, G., 2013. Multi-floor buildings and human wayfinding gnition. Behavioral and Brain Sciences, 36(5), pp. 551-552.

Hölscher, 6 et al., 2006. Up the down staircase: Wayfinding strategies in multi-level buildings. Journal of Environmental Psychology, 26(4), pp. 284-299.

Hölscher, C, Tenbrink, T. \& Wiener, J., 2011. Would you follow your own route description? Cognitive strategies in urban route planning. Cognition, 12(2), pp. 228-247.

ISO, 2011. ISO 14825 Intelligent transport systems, Geographic Data Files (GDF 5.0), Vernier: International Organization for Standardization.

Jayasinghe, A., Sano, K., Abenayake, G. \& Mahanama, P., 2019. A novel approach to model traffic on road segments of large-scale urban road networks. MethodsX, Volume 6, pp. 1147-1163..

Jeffery, K., 2019. Urban Architecture: A Cognitixe Neuroscience Perspective. The Design Journal, 22(6), pp. 853-872..

Jiang, B. \& Claramunt, C., 2002. Integration of space syntax into GIS: new perspectives for urban morphology. Transactions in GIS, 6(3), pp. 295-309.

Kang, C., 2017. Measuring the effects of street network configurations on walking in Seoul, Korea. Cities, Volume 71, pp. 30-40.

Kim, M., Jeffery, K. J. \& Maguire, E. A., 2017. Multivoxel pattern analysis reveals 3D place information in the human hippocampus. Journal of Neuroscience, 37(16), pp. 4270-4279.

Kondyli, V. \& Bhatt, M., 2018. Rotational locomotion in large-scale environments. A survey and implications for evidence-based design practice. Built Environment, 44(2), pp. 241-258.
Kuliga, S. et al., 2019. Exploring individual differences and building complexity in Wayfinding: The case of the seattle central library. Environment and Behavior, 51(5), pp. 622-665.

Lee, J., 2004. A spatial access-oriented implementation of a 3-D GIS topological data model for urban entities. Geolnformatica, 8(3), pp. 237-26.

Li, R. \& Klippel, A., 2016. Wayfinding behaviors in complex buildings: The impact of environmental legibility and familiarity. Environment and Behavior, 48(3), pp. 482-510.

Long, Y. \& Baran, P., 2012. Does intelligibility affect place legibility? Understanding the relationship between objective and subjective evaluations of the urban environment. Environment and Behavior,, 44(5), pp. 616-640. 
How 3D complex network volumetrics improve analysis

Lu, Y. \& Ye, Y., 2017. Can people memorize multilevel building as volumetric map? A study of multilevel atrium building. Environment and Planning B: Urban Analytics and City Science, pp. 1-18.

Lynch, K., 1960. The image of the city. Cambridge (MA): MIT press.

Mangin, D., Girodo, M. \& Architecture, S., 2016. Mangroves urbaines. Paris: La Découverte.

Marshall, S., 2005. Street and Patterns. New York, NY: Spon Press.

Marshall, S., 2016. Line structure representation for road network analysis. Journal of Transport and Land Use, 9(1), pp. 29-64.

Marshall, S. et al., 2018. Street network studies: from networks to models and their representations. Networks and Spatial Economics, 18(3), pp. 735-749.

McNeill, D. 2019. Volumetric urbanism: The production and extraction of Singaporean territory. Environment and Planning A: Economy and Space, 51(4), pp. 849-868.

Millonig, A. \& Schechtner, K., 2007. Decision loads and route qualities for pedestrians-Key requirements for the design of pedestrian navigation services. In: N. Waldau, G. P, H. Knoflacher \& M. Schreckenberg, eds. Pedestrian and evacuation dynamics . Berlin: Springer, pp. 109-118.

Montello, D., 2007. The contribution of space syntax to a comprehensive theory of environmental psychology. In: A. Kubat, O. Ertekin, Guney \& E. Eyuboglu, eds. Proceedings of the 6th International Space Syntax Symposium 12-15 June. Istanbul: Istanbul Technical University, pp. iv-1-12.

Montello, D. R., 2005. Navigation. In: P. Shah \& A. Miyake, eds. The Cambridge handbook of visuospatial thinking. Cambridge University Press. New York, NY: Cambridge University Press, pp. 257-294.

Oliveira, V., 2016. The study of urban form: Different approaches. In: Urban morphology. Cham: Springer, pp. 87-149.

O'Neill, M., 1991. Evaluation of a conceptual model of architectural legibility. Environment and Behavior, 23(3), pp. 259-284..

Pafka, E., Dovey, K. \& Aschwanden, G., 2020. Limits of space syntax for urban design: Axiality, scale and sinuosity. Environment and Planning B: Urban Analytics and City Science, 47(3), pp. 508522.

Penn, A., 2003. Space syntax and spatial cognition: or why the axial line?. Environment and behavior, 35(1), pp. 30-65.

Rashid, M., 2019. Space Syntax: A Network-Based Configurational Approach to Studying Urban Morphology. In: L. D'Acci, ed. The Mathematics of Urban Morphology. Cham: Birkhäuser, pp. 199250.

Ratti, C., 2004. Space syntax: some inconsistencies. Environment and Planning B: Planning and Design, 31(4), pp. 487-499. 
How 3D complex network volumetrics improve analysis

Richter K, F., 2009. Adaptable Path Planning in Regionalized Environments. In: S. Hornsby K, C. Claramunt, D. M \& L. G, eds. Spatial Information Theory. COSIT 2009. Lecture Notes in Computer Science, Vol 5756. Berlin, Heidelberg: Springer, pp. 453-470.

Salheen, M. \& Forsyth, L., 2001. Addressing distance in the space syntax syntactical model. Urban Design International, 6(2), pp. 93-110.

Samant, S., 2019. Cities in the Sky: Elevating Singapore's Urban Spaces. International Journal of High-Rise Buildings, 8(2), pp. 137-154.

Sharmin, S. \& Kamruzzaman, M., 2018. Meta-analysis of the relationships between space syntax measures and pedestrian movement. Transport Reviews, 38(4), pp. 524-550.

Shatu, E., Yigitcanlar, T. \& Bunker, J., 2019. Shortest path distance vs. least directional change: Empirical testing of space syntax and geographic theories concerning pedestrian route choice behaviour. Journal of Jransport Geography, Volume 74, pp. 37-52.

Shelton, B., Karakiewicz, J. \& Kvan, T., 2011. The Making of Hong Kong: From Vertical to Volumetric.. New York, NY: Routledge.

Sun, G., Webster, C. \& Zhang, X. 2019 Connecting the city: a three-dimensional pedestrian network of Hong Kong. Environment and Planning B: Urban Analytics and City Science, pp. 1-16.

Tang, B., Wong, K., Tang, K. \& Wong, S, 2021. Watking accessibility to neighbourhood open space in a multi-level urban environment of Hong Kong. Environment and Planning B: Urban Analytics and City Science, 48(5), pp. 1340-1356.

Tan, Z. \& Xue, C., 2014. Walking as a planned activity: Elevated pedestrian network and urban design regulation in Hong Kong. Journal of Urban Design, 19(5), pp. T22-744..

Thibault, G. et al., 2013. How does horizontal and vertical navigation nfluence spatial memory of multi-floored environments. Attention, Perception, and Psychophysics, 75(1), pp. 10-15.

Transport Department, 2014. Travel Characteristics Survey 2011 FinarReport, Hong Kong: s.n.

Turner, A., 2007. From Axial to Road-Centre Lines: A New Representation for Space Syntax and a New Model of Route Choice for Transport Network Analysis. Environment and Planning B. Planning and Design, 34(3), pp. 539-555.

Turner, A., Doxa, M., O'Sullivan, D. \& Penn, A., 2001. From isovists to visibility graphs: a methodology for the analysis of architectural space. Environment and Planning B: Planning and Design, 28(1), pp. 103-121.

Turner, A., Penn, A. \& Hillier, B., 2005. An Algorithmic Definition of the Axial Map. Environment and Planning B: Planning and Design, 32(3), pp. 425-444.

Vanclooster, A. \& De Maeyer, P., 2012. Combining indoor and outdoor navigation: The current approach of route planners. In: G. Gartner \& F. Ortag, eds. Advances in Location-Based Services. Berlin, Heidelberg: Springer, pp. 283-303. 
How 3D complex network volumetrics improve analysis

Vanclooster, A., Van de Weghe, N., Fack, V. \& De Maeyer, P., 2014. Comparing indoor and outdoor network models for automatically calculating turns. Journal of Location Based Services, 80(3), pp. 148-165.

Varoudis, T., 2012. depthmapX multi-platform spatial network anlysis software Version 0.30 OpenSource. [Online]

Wedderburn, M. \& Chiaradia, A., 2014. Network, Network, Network: New Techniques in Pedestrian Movement Analysis. In: 42nd European Transport Conference. Frankfurt, 10-17 Sept: Association for European Transport (AET), pp. 1-13.

Weisman, J., 1981. Evaluating architectural legibility: Way-finding in the built environment. Environment and behavior, 13(2), pp. 189-204.

Woollett, K. \& Maguire, E., 2011. Acquiring "the Knowledge" of London's layout drives structural brain changes. Current biglogy, 21(24), pp. 2109-2114.

Xue, L. C. Q., 2016. Rail Village and Mega-Structure. In: Hong Kong Architecture 1945-2015. Singapore: Springer.

Xu, J. et al., 2020. Indoor-Outdoor Navigation without Beacons: Compensating Smartphone AR Positioning Errors with 3D Pedestrian Network. In.M. Asmar, P. Tang \& D. Grau, eds. Construction Research Congress 2020: Infrastructure Systems and Sustainability. Reston, VA: American Society of Civil Engineers, pp. 444-452.

Yan, J., Diakité, A. A. \& Zlatanova, S., 2019. A generic space definition framework to support seamless indoor/outdoor navigation systems. Transactions in GIS, 23(6), pp. 1273-1295.

Yan, J., Zlatanova, S. \& Diakité, A., 2021. A unified 3D space-based navigation model for seamless navigation in indoor and outdoor. International Journal of Digital Earth, pp. 19.

Yoos, J. \& James, V., 2016. Parallel Cities: The Multilevel Metropolis. Minneapolis, MN: Walker Art Center.

Zandbergen, P. A., Ignizio, D. A. \& Lenzer, K. E., 2011. Positional accuracy of TIGER 2000and 2009 road networks. Transactions in GIS, 15(4), pp. 495-519.

Zhang, L., Chiaradia, A. \& Zhuang, Y., 2013. In the intelligibility maze of space syntax: a space syntax analysis of toy models, mazes and labyrinths. In: Y. Kim, H. Park \& K. W. Seo, eds. Proceedings of the Ninth International Space Syntax Symposium. Seoul: Sejong University, pp. 082:1-082:18.

Zhang, L., Chiaradia, A. \& Zhuang, Y. A., 2015. Configurational Accessibility Study of Road and Metro Network in Shanghai. In: Q. Pan \& J. Cao, eds. Recent Developments in Chinese Urban Planning. Heidelberg: Springer, pp. 219-245. 
How 3D complex network volumetrics improve analysis

Zhao, J., Sun, G. \& Webster, C., 2020. Walkability scoring: Why and how does a three-dimensional pedestrian network matter?. Environment and Planning B: Urban Analytics and City Science, p. 2399808320977871.

Zhou, Y., Dao, T. H. D., Thill, J. C. \& Delmelle, E., 2015. Enhanced 3D visualization techniques in support of indoor location planning. Computers, Environment and Urban Systems, 1(50), pp. 15-29.

Zimring, C. \& Dalton, R., 2003. Linking objective measures of space to cognition and action. Environment and Behavior, 35(1), pp. 3-16. 


\section{Supplementary Materials (S)}

\section{Contents}

S01: Outdoor pedestrian network encoding, link, and node 2

-S02: Pedestrian Path Network spatial models 2

S03: Medial/Centre line spatial model in space syntax 4

aS04: Case study selection 4

-S05. Axial Maps, “inherent intelligibility” plot 5

-S06: HKSAR 3D Pedestrian Network (3DPN) data model 7

-S07: Study area from Sheung Wan to Wan Chai 8

-S08: Pedestrian Data Collection 8

-S09: Pedestrian surveys sampling area effects on closeness and betweenness 9

-S10: Medial/Centre line spatial model in space syntax (Chang \& Penn, 1998) 11

-S11: Chang \& Penn, 1998, Barbican, Axial line, and mixed axial line spatial model principles 12

-S12: Subset of the spatial model defined by a reach radius based on 3D network 12

-S13: All results of Bivariate Regression Analysis between observed pedestrian flow and betweenness \& closeness measures according to each radius 13

-S14: Detailed Description of the results 14

-S15: Method of calculating volumetric density and network density within $400 \mathrm{~m}$ of each observation cordon 16

-S16: Model of the role of morphological "inherent" intelligibility and enactivism framework of intelligibility

- Table ST1: Link types with description and enumeration of the 3Dindoor-outdoor path-centre line map of the study area.

- Table ST2: Summary of the literature review analysing spatial complexity using 3D visibility/isovist analysis.

- Table ST3: Descriptive statistics of all 33 observed cordon counts.

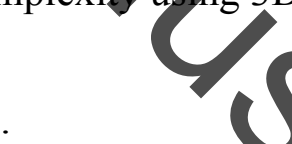

- Table ST4: Descriptive statistics of Axial map 2.5D, segment map 2.5D, 3D outdoo path-centre line map, and complete 3D indoor and outdoor path-centre line map.

- Table ST5: Bivariate Regression Analysis, highest R-square coefficient of determination between Ln pedestrian movement and Ln betweenness/Ln Closeness measures for the nine spatial models, $(\mathrm{N}=33)$.

- Table ST6: Multivariate Stepwise Regression Analysis Results and normality test

- References 


\section{S01 Outdoor pedestrian network encoding, link, and node}

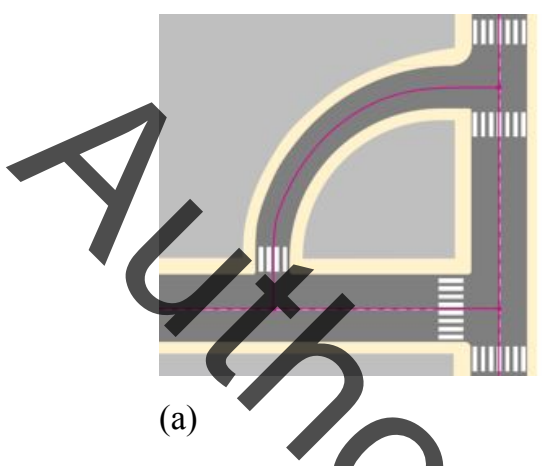

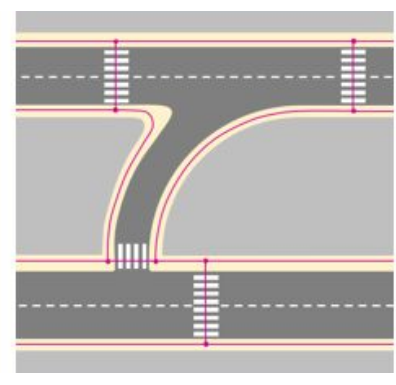

(b)

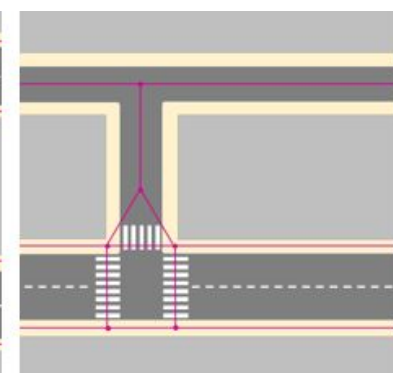

(c)

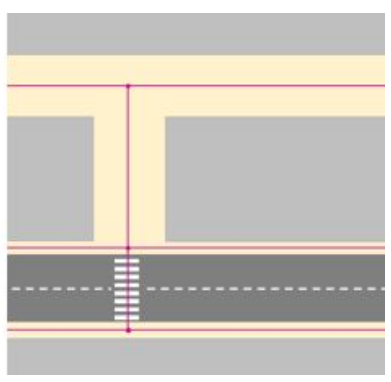

(d)

Figure S01: Outdoor pedestrian network encoding, link, and node: a. 2D road centre line encoding; b. desegregated 2D medial centre path pedestrian network; c. \& d. mixed aggregated/desegregated 2D medial pedestrian spatial model - c. link and node. residential streets with low traffic and no formalized crossing linked to a street with formalized crossings; $\mathbf{d}$. link and node; pedestrianized streets linked to a street with formalized crossings.

\section{S02: Pedestrian Path Netyork Spatial Models}

The first two spatial models (Table ST5 (1) \& (2)) are the space syntax's axial map, and the segment map which is derived from the axial map (Hillier \& Iida 2005). The axial map follows the mixed axial mapping principles as shown in Chang and Penn 1998 (see Figure S10 below). The next two spatial models (Table ST5 (3) \& (4)) are disaggregated with the two sides of the street using axial map and the derived segment nap.

For the segment map each axial line is broken at intersections, allowing for a higher spatial level of definition and analysis of the streets (Hillier \& Hanson, 1984; Hillier \& Iida, 2005; Turner, et al., 2005). A curve link is broken in multiple short segments (figure S02). To emulate the 3DPN (HKSAR LandsD, 2020) in the study area, as suggested by Chang and Penn (1998, pp. 511-513), outdoor overground and underground pedestrian networks are mapeec in the same plane as a single axial line system, connected with an additional line to ground level and disconnected through "unlinks", making the 2D axial map 2.5D. As suggested by Hanson (1994, pp. 679, 684, 690) and Hanson (1998, pp. 246-256) indoor multilevel having floor plan side by sidedn the same plane and either manually linking the floors (Hanson, 1998, pp. 246-256) or by manually linking an additional axial line standing for any type of vertical circulation (Hölscher, etal p. 69). In the study area, it is not possible to combine these "work arounds" for 3D indoor and outdoor as a large number of traversable buildings (70) with multiple publicly accessible floo would require to manually create more than a thousand "unlinks". 

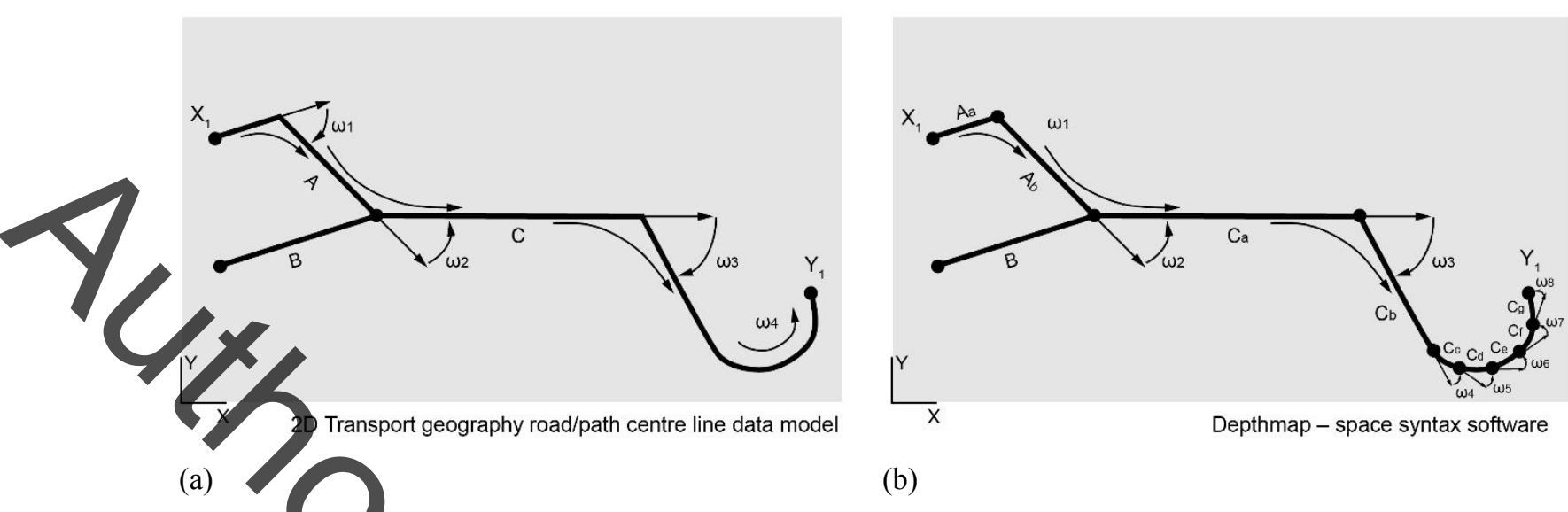

Figure S02: 2D Transport geography road/path centre line data model and DepthmapX - space syntax software operationalization of angular analysis: a. 3 links, 4 decision nodes, Angular change along the route X1Y1= $\sum w 1, w 2, w 3, w 4$, sDNA (Cooper \& Chiaradia, 2020). b. axial segment (space syntax - Depthmap, (Turner, 2007; depthmapX development team, 2017-19), 10 segments, 11 decision nodes, Angular change along the route X1Y1= $\sum w 1, w 2, w 3, w 4, w 5, w 6, w 7, w 8$.

The fifth spatial model is the 3 Dpedestrian path-centre line map from the 3DPN (HKSAR LandsD, 2020), which defines links as the connection between two adjacent junctions, or between a junction and a dead-end on to itseff(roundabout dead-end) (Cooper \& Chiaradia, 2020). The principles of these detailed 3R spatial models are shown in Fig. 2. It includes both sides of the street, terrain topography, actual height between floor level, publicly accessible at grade, over ground, and underground pedestrian paths, fint and the path centre line geometry of escalator, stair, ramp, and slope.

The spatial models (3), (4), (5) (Table ST5) have each a yariant (Table ST5 (3v), (4v), (5v)), to test the impact of omitting or including publicly accessible fidoor pedestrian network on the association between pedestrian movement patterns and the measure of tayout complexity. The 3DPN has a simplified pedestrian indoor network (PIN) (Cooper \& Chiaradia, 2014; Sun, et al., 2019; HKSAR LandsD, 2020) used for the spatial models (3v), (4v), (5v) to enabletheir comparison, due to the practical impossibility of operationalizing the axial and derived segment maps in a 3D complex multi-level indoor environment. The PIN is shown as orange fines in Figures S11a to S11c. This is to maintain a moderate level of realism of movement contrintity between the indoor and outdoor pedestrian realms, a characteristic of volumetric urbanism. The PIN, added to the outdoor multi-level pedestrian network, does not provide an accurate spatial model of publicly accessible indoor paths, but it allows for a fair comparison of the axial line and segment 2.5D spatial models and 3D spatial models with a simplified indoor network. 
The sixth spatial model is an enhanced version of the 3DPN (HKSAR LandsD, 2020). It adds to the $3 \mathrm{D}$ outdoor pedestrian network, the complete $3 \mathrm{D}$ indoor pedestrian network with the configuration details of vertical transitions (lifts, escalator, stair, and ramps) following the same data model principle as the 3DPN. The fourth spatial model is a 3D high-resolution, highdefinition map of indoor and outdoor path-centre lines of the pedestrian network (Figure 4d). Within the study area, all the traversable buildings' floors connected to pedestrian pathways at ground and overground, or at ground and underground or at ground, underground and overground were mapped, including vertical transitions, to provide a complete 3D indoor \& outdoor pedestrian network. The digital floor plans and sections of more than 70 buildings were retrieved from the HK Burlding Department's BRAVO database (HKSAR BD, 2020). Figure 5a, for example, shows the 3Dinclor \& outdoor network of the Hong Kong station and IFC mall. Actual heights are used for vertical transitions.

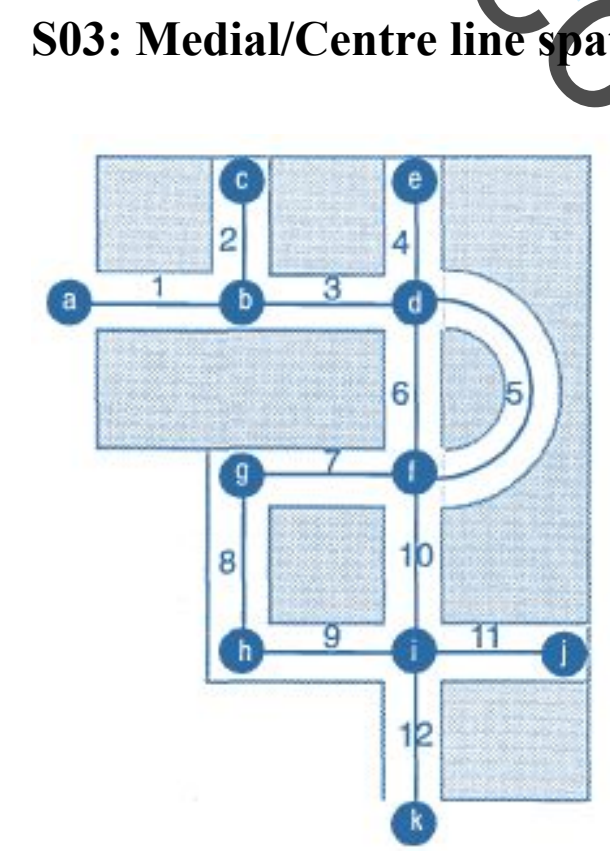

Figure S03: From Chang \& Penn (1998, p. 525): The suggested medial/centre line spatialmodel. It is inconsistent as it is a mix of continuity medial line $(5)$ and discontinuous medial line $(7,8,9)$ with superfluous node ( $\mathrm{g} \& \mathrm{~h})$.

\section{S04 Case study selection}

As Chang and Penn (1998), use the exceptional South Bank and Barbican as case studies in London to "tackle the issue of the degree to which it is possible to make predictions of patterns of pedestrian movement in large and relatively unintelligible multilevel urban complexes." Similarly, we propose an extreme case research strategy (Flyvbjerg, 2001). Extreme case study strategy is 
well suited to get across the point about the hypothesised relationship between "inherent" intelligibility and pedestrian predictability. The case is critically selected on the base of expected content: selecting a study area with intelligibility close to zero, as in Chang and Penn (1998) and using the same spatial modelling, the axial line system, we are expecting low predictability of pedestrian flow patterns. By showing that predictability of pedestrian flow is high would permit us to conclude that if "inherent" intelligibility" is not valid for this case, then it applies to all the cases (Flyybjerg, 2001, p. 79).

Paralleling Chang \& Penn's (1998) selection criteria of exceptional urban conditions, we select Central in Hong Kong, which is an extreme case of central mixed-use development, with pedestrian segregation linked to attractors/generators such as mass transit stations. Such development can be found in all Hong Kong new towns where more than $60 \%$ of the population live.

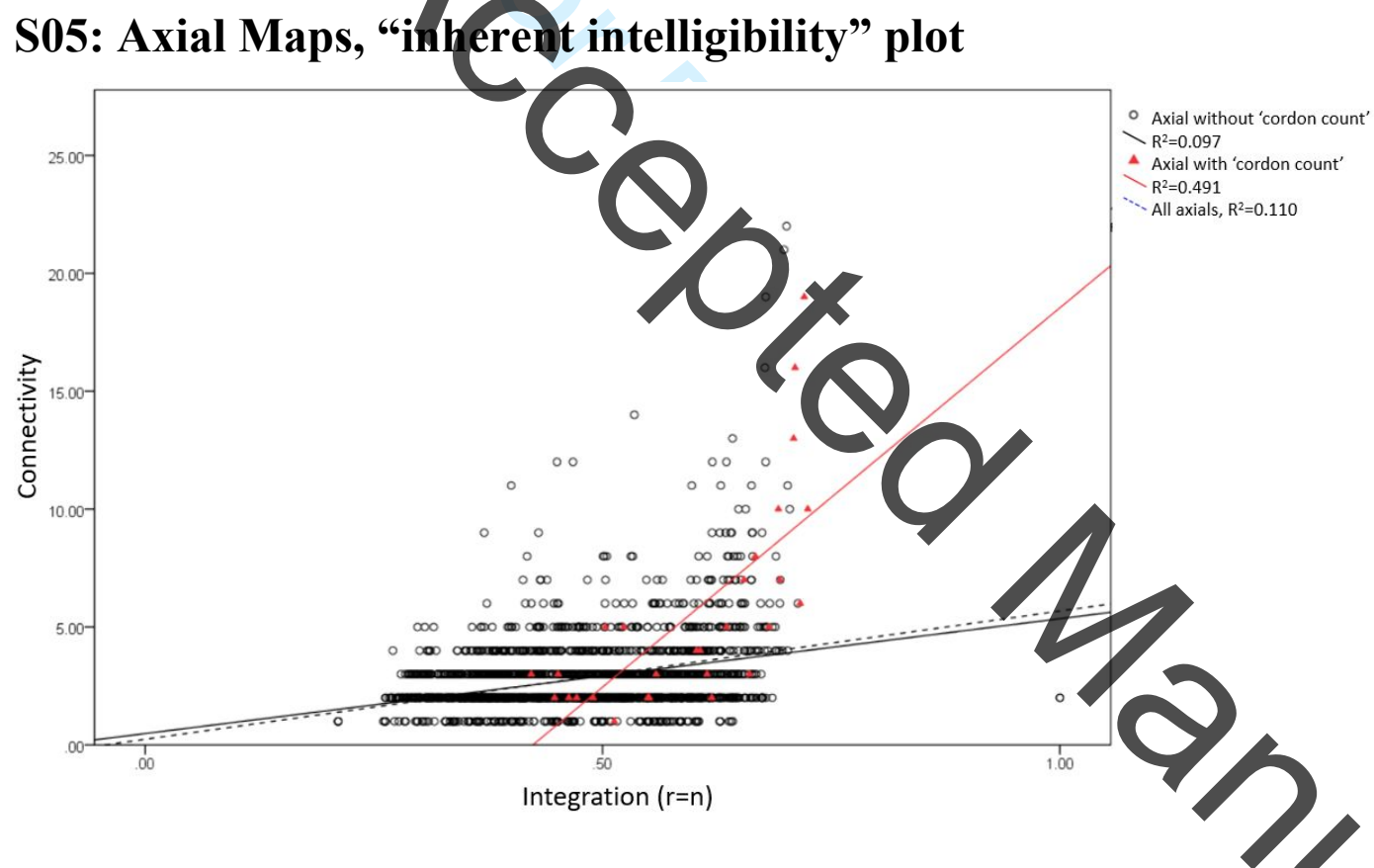

Figure S05a: Hong Kong Central, Axial standard and no PIN. Linear univariate regression of Degree (Connectivity) and Closeness N (Integration N) R ${ }^{2}=0.110$ overall and 0.491 for cordon count. For reference for the two areas in central London, Chang and Penn's multi-level study (1998) shows that intelligibility R ${ }^{2}$ values were 0201 and 0.41.

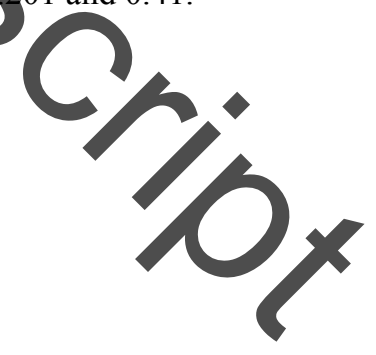




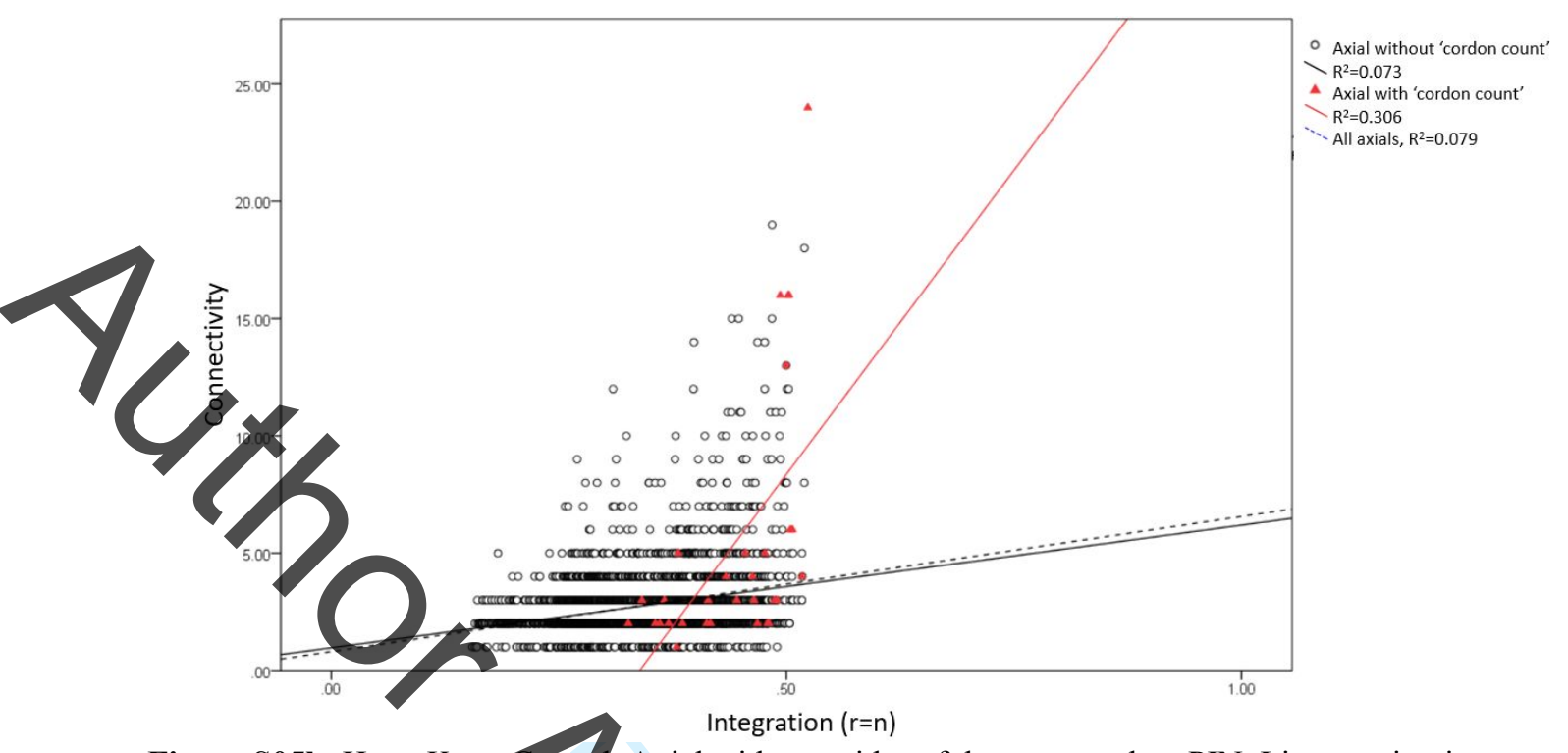

Figure S05b: Hong Kong Central, Axial with two sides of the street and no PIN. Linear univariate regression of Degree (Connectivity) and Closeness N (Integration N) $\mathrm{R}^{2}=0.079$ overall and 0.306 for cordon count

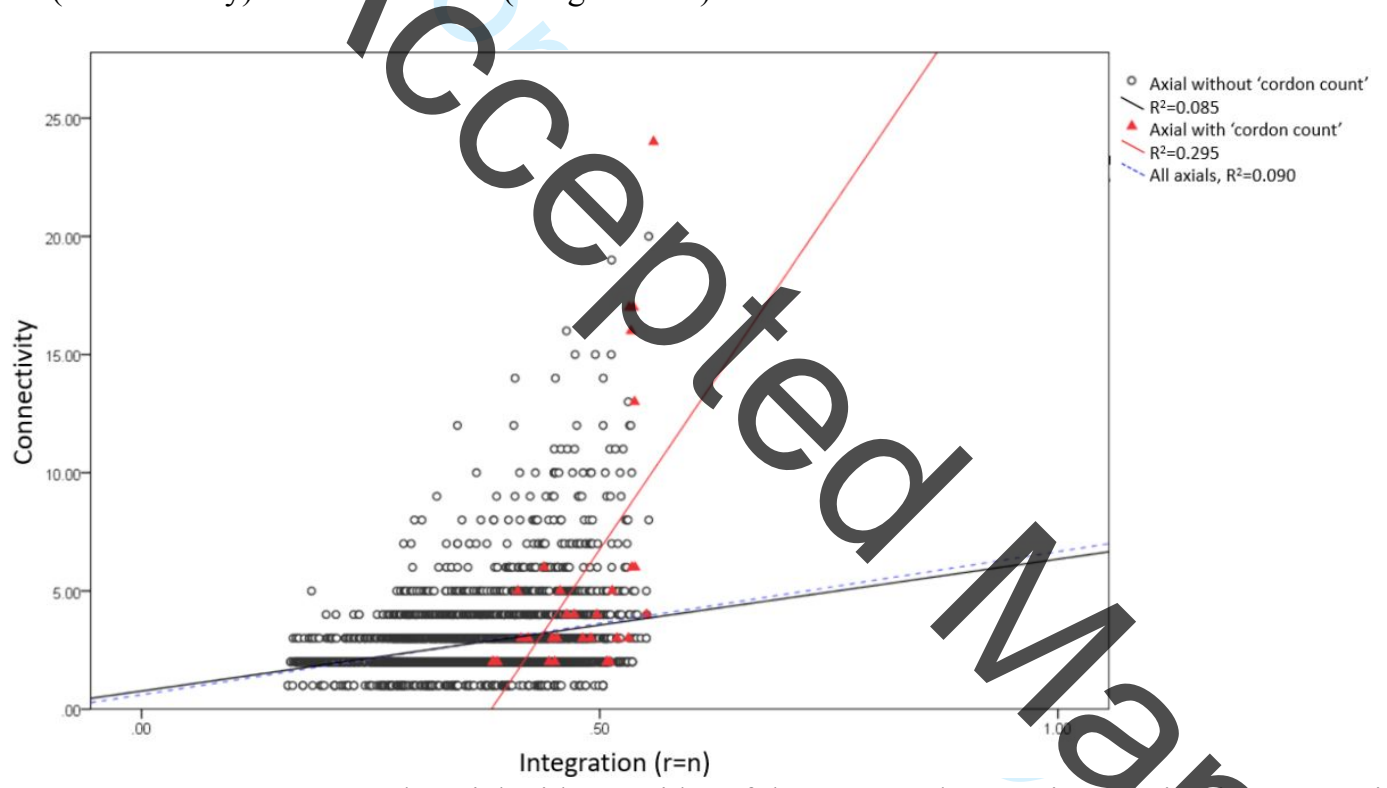

Figure S05c: Hong Kong Central, Axial with two sides of the street and PIN. Linear univariate regression of Degree (Connectivity) and Closeness $\mathrm{N}$ (Integration N) $\mathrm{R}^{2}=0.09$ overall and 0.295 for cordon count.

Table S xx: Summary: Intelligibility, $\mathrm{R}^{2}$ between Connectivity \& Integration (Rn).

\begin{tabular}{|c|c|c|c|}
\hline & $\begin{array}{l}\text { All } \\
\mathrm{R}^{2} \\
\end{array}$ & $\begin{array}{c}\text { All 'cordon count' } \\
\mathrm{R}^{2} \\
\end{array}$ & All without 'cordon count' \\
\hline Fig. S08a: one line standard-mixed axial spatial model, no PIN & 0.110 & 0.491 & 0.097 \\
\hline Fig. S08b: two lines (two sides of the street) axial spatial model, no PIN & 0.079 & 0.306 & 0.0 \\
\hline Fig. S08c: two lines (two sides of the street) axial spatial model with PIN & 0.090 & 0.295 & \\
\hline
\end{tabular}




\section{S06: HKSAR 3D Pedestrian Network (3DPN)}

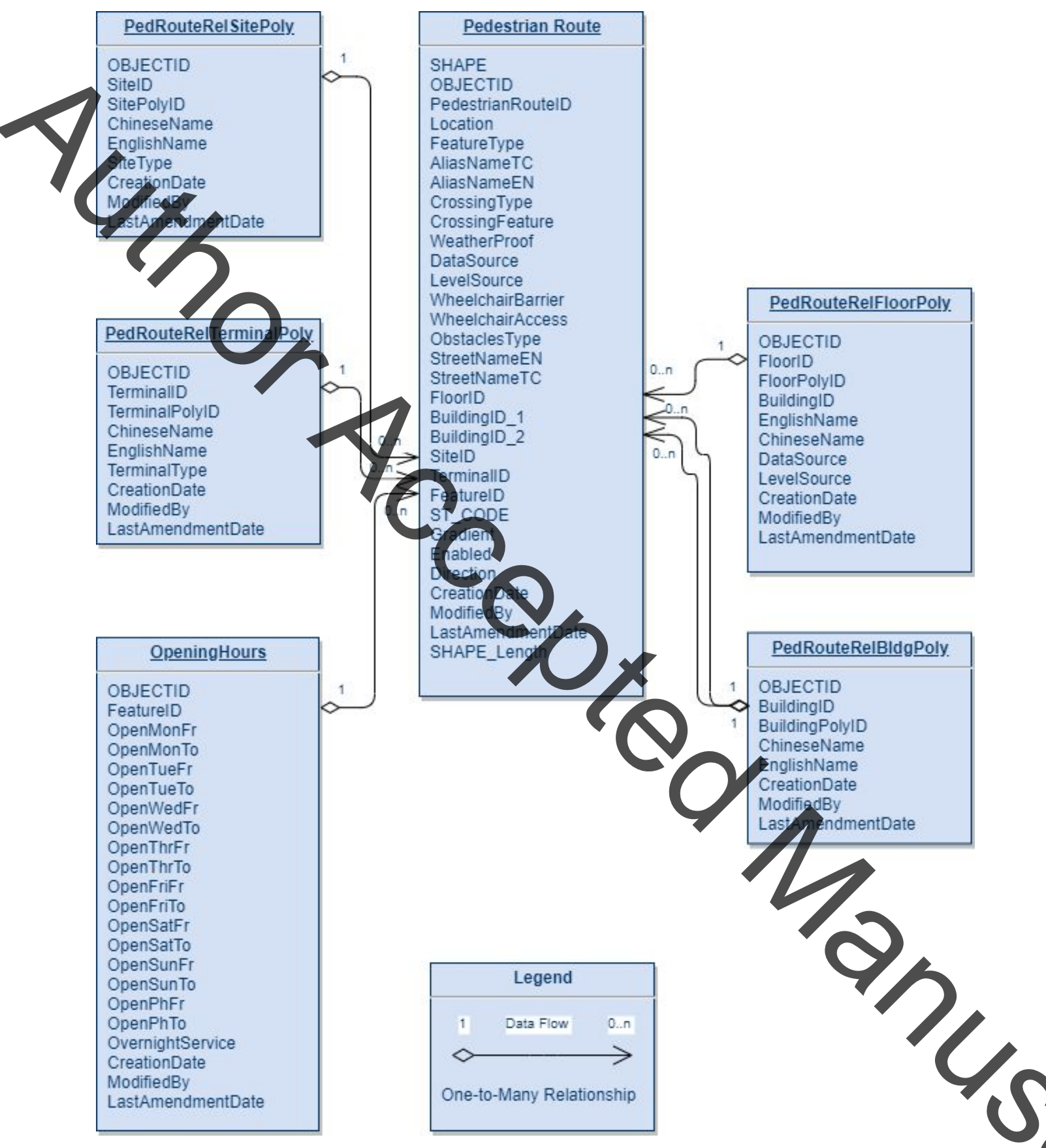

Figure S06: HKSAR 3D Pedestrian Network, data model (JSON, GML, FGDB)

API: https://geodata.gov.hk/gs/view-dataset?uuid=201 eaaee-47d6-42d0-ac81-19a430f63952\&sidx=0 Data Dictionary: https://geodata.gov.hk/gs/download-datadict/201eaaee-47d6-42d0-ac81-19a430f63952 


\section{S07: Study area from Sheung Wan to Wan Chai}

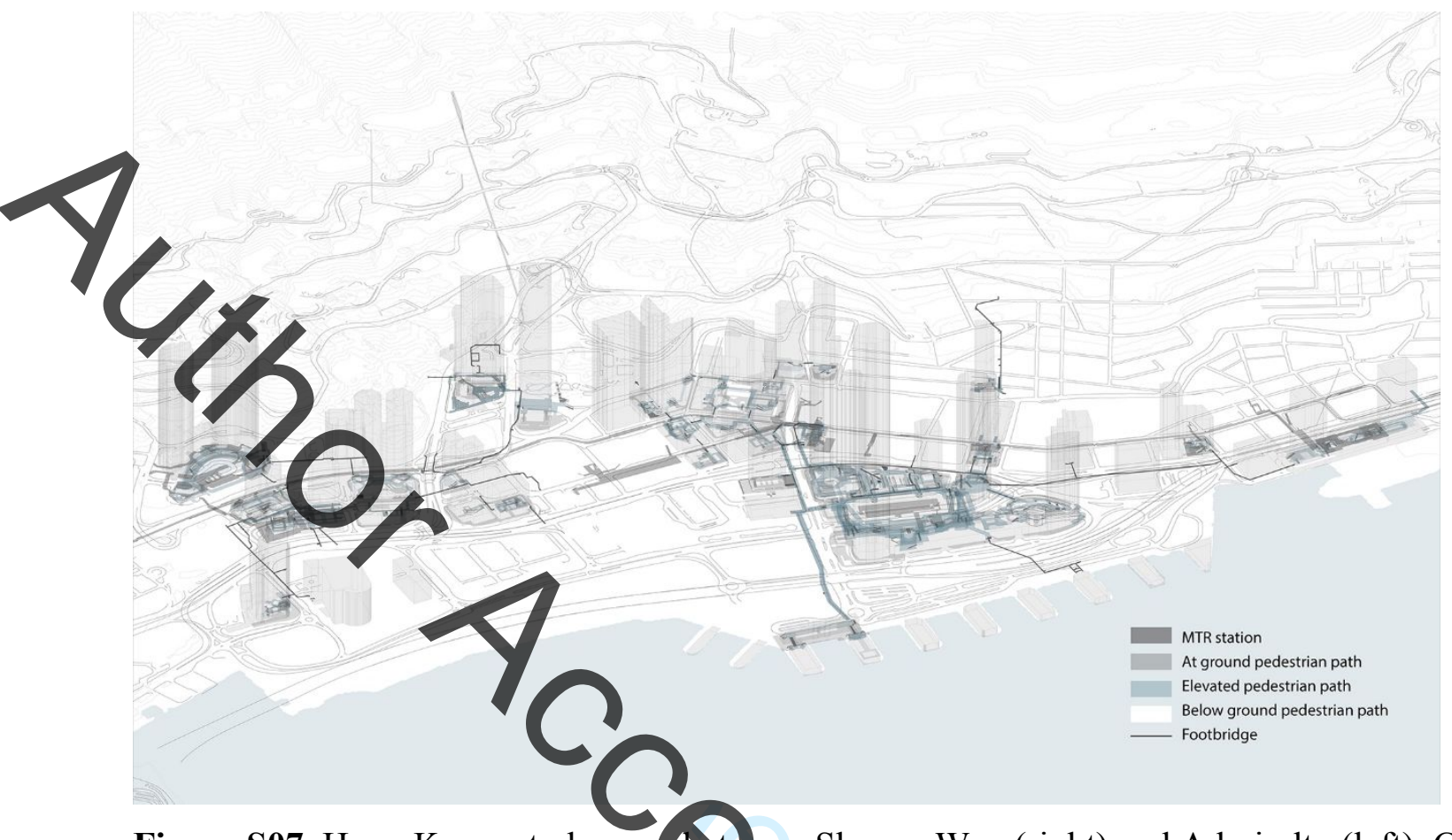

Figure S07. Hong Kong, study area, between Sheung Wan (right) and Admiralty (left), Central (middle) volumetric mega-structure connecting 70 traversable buildings with multiple access at different levels.

\section{S08: Pedestrian Data Collection}

The 'Cordon Count' method of observation (Chang\& Penn, 1998; Spencer \& Wedderburn, 2007) was used for gathering pedestrian volume data within $300 \mathrm{~m}$ buffer areas $(1.2 \times 1 \mathrm{~km})$ from the entrances/exits of the Central and Hong Kong MTR stations (Figure S1). To avoid the edge effect, the pedestrian network is mapped using an extended boundary, an $800 \mathrm{~m}$ radius straight line buffer area from the MTR exits. The observations were recorded for 30 minutes at each location, distributed over six different periods for one weekday: 8-10 am, 10-noon, noon-2 pm, 3$5 \mathrm{pm}, 5-7 \mathrm{pm}$, and 7-9 pm. A total of 17,307 pedestrians were counted on 33 pedestrian network links. The pedestrian flows on the skywalk are higher than those at ground level. 


\section{Network based cognitive urban volumetrics}

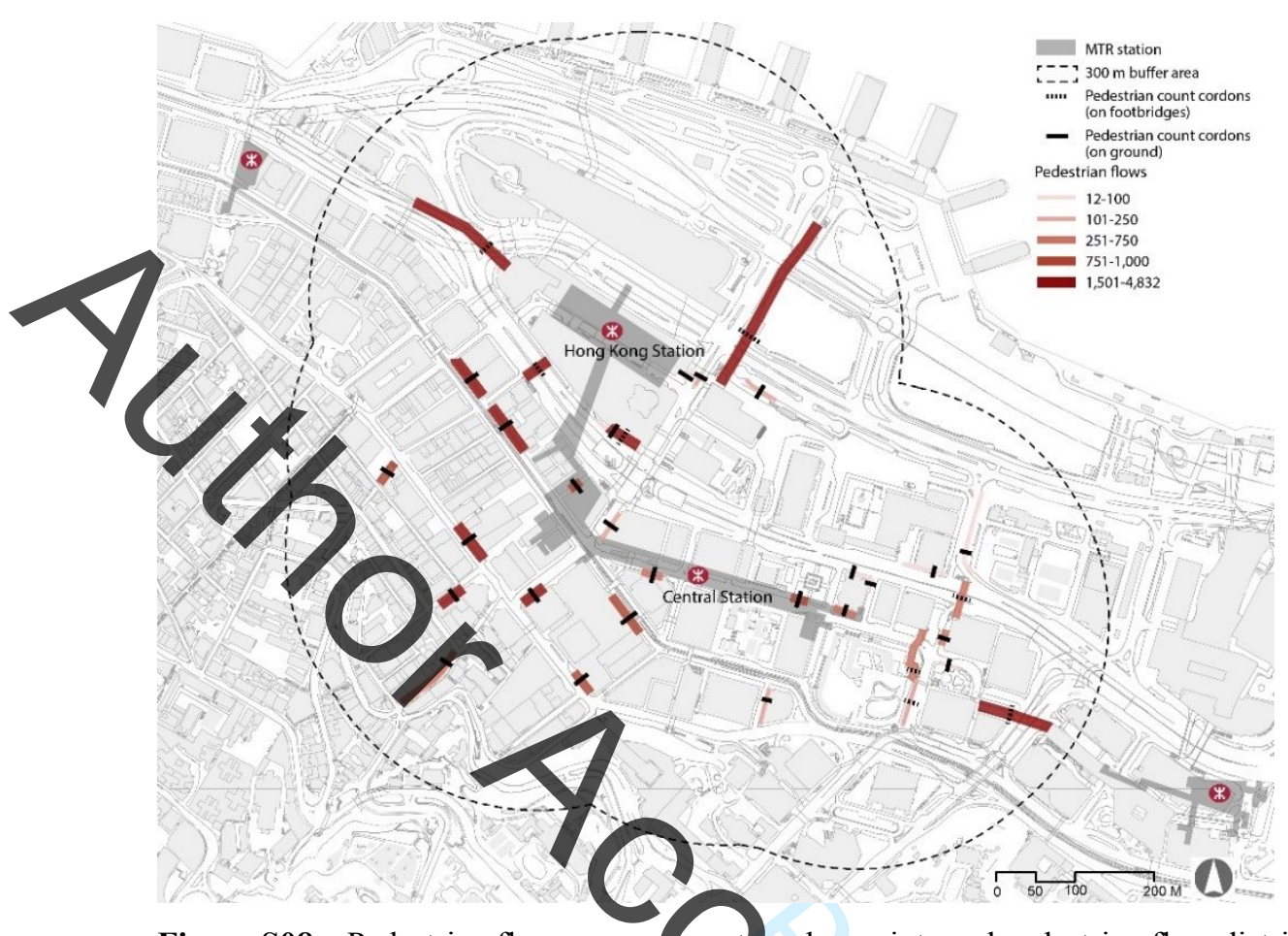

Figure S08a. Pedestrian flow measurement cordon points and pedestrian flow distribution.

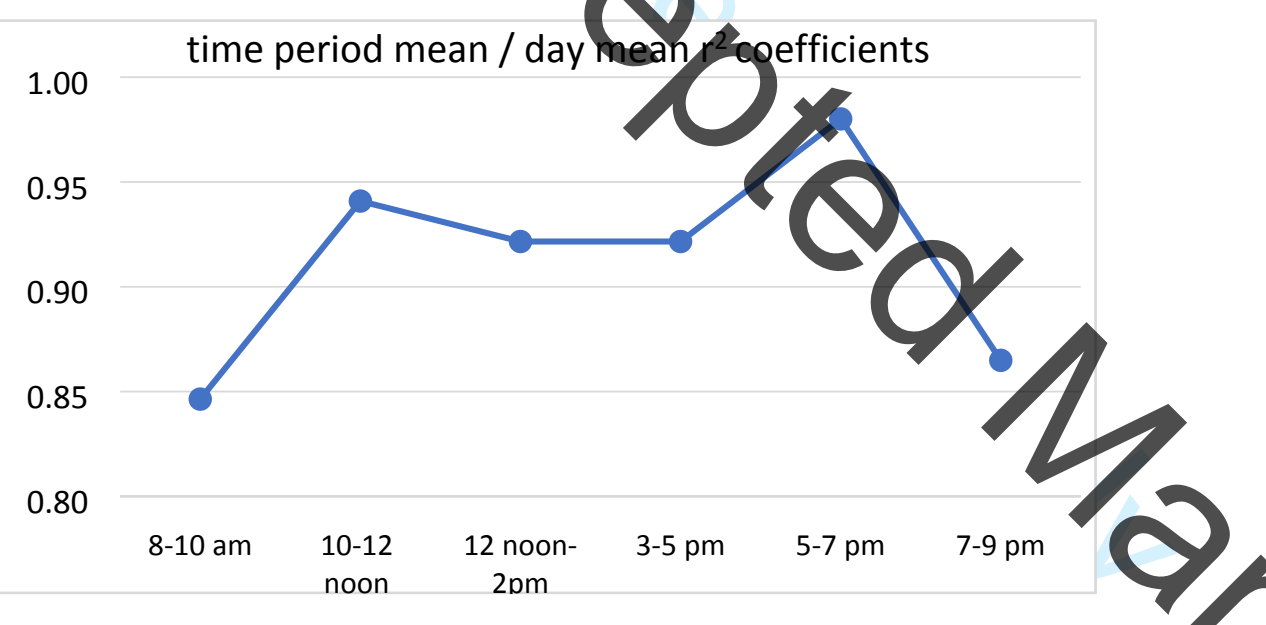

Figure S08b. Correlation flow rates among all-day average and each period (Central, 33 cordons)

Finally, video surveys were done over three weekdays from 7 am to 10 pn for every $5^{\text {th }} 15$ min period that matched the location of the initial manual survey in Figure S08a $(\mathbb{N}=73,674)$. This type of survey has an estimated margin of error of $\pm 4 \%$ for average weekdays for the specified time of the year (Spencer \& Wedderburn, 2007). The initial manual survey is highly correlated $\left(\mathrm{R}^{2} \approx 0.97\right)$ corroborating the robustness of the findings. Also see S09.

\section{S09: Pedestrian surveys}

A pedestrian survey dataset gathered from one-day of camera recordings of 28 cordons for a wider area from Sheung Wan to Wan Chai (Figure S09a) showed that the association with 
pedestrian flow for the betweenness values of an outdoor only pedestrian network and an indooroutdoor 2.5D pedestrian network segment spatial model and full 3D transport geography spatial model were $\mathrm{R}^{2}=0.29$ and $\mathrm{R}^{2}=0.64$ respectively (Zhang \& Chiaradia, 2019; Zhang \& Chiaradia

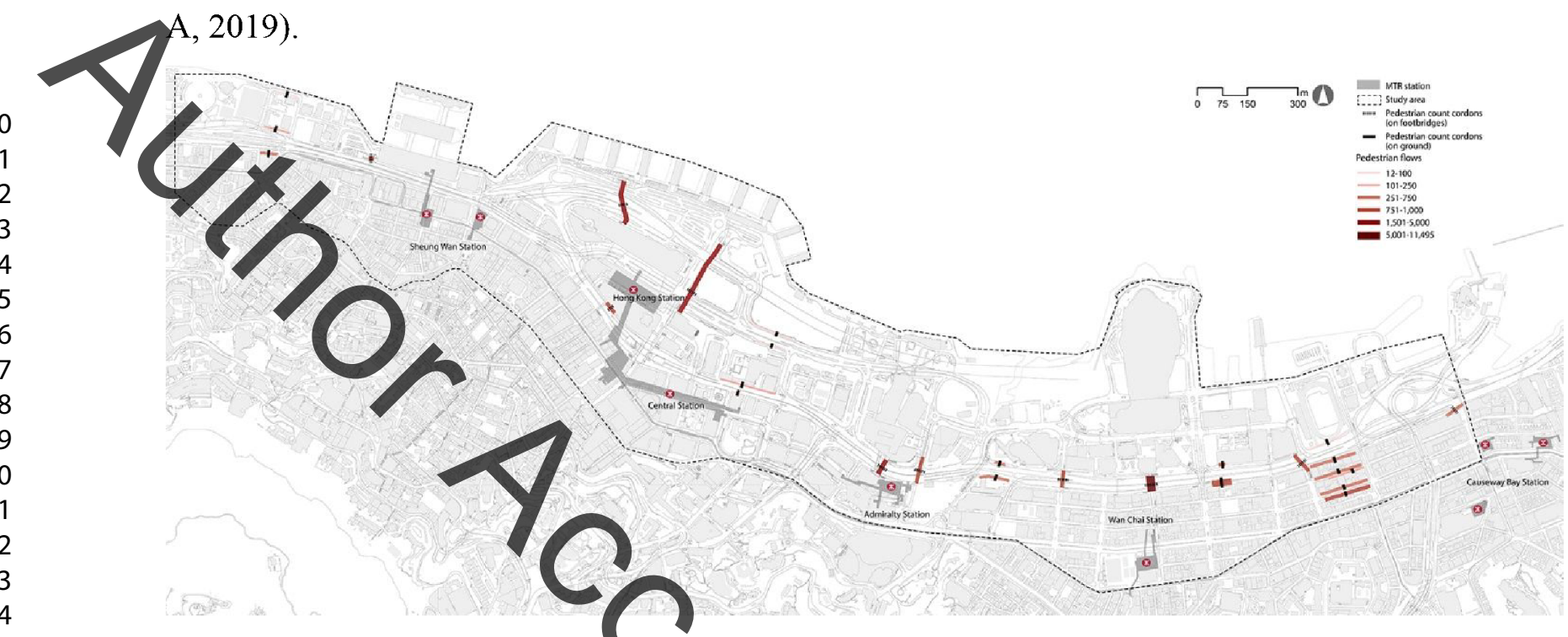

Figure S09a. Pedestrian flow distribution of 28 cordons for a wider area $(\mathrm{N}=293,625)$.

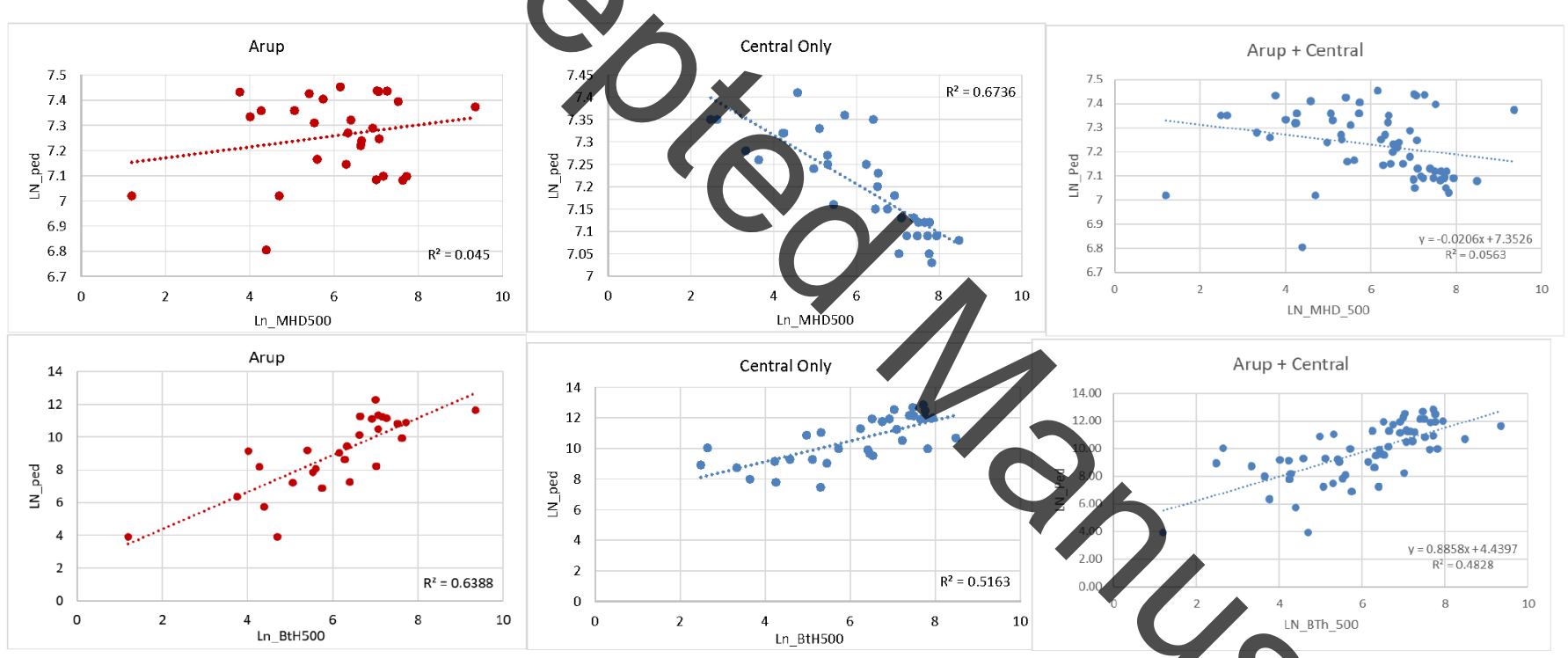
(a) A wider area with 28 cordon counts
(b) Central area with 33 cordon counts
(c) all $28+33$ cordons counts

Figure S09b. Closeness top row, Betweenness bottom row. With 61 pedestrian cordon counts $(\mathrm{N}=293,625)(\mathrm{c})$, it is found that closeness has no correlation $\left(\mathrm{R}^{2}=0.06\right)$ and betweenness has a high correlation $\left(\mathrm{R}^{2}=0.48\right)$. Sampling location affects the results. These variations need further investigations. 


\section{S10: Chang \& Penn, 1998 Barbican, standard Axial line, and mixed spatial model principles}

Red: Permeability, no visibility, mapped with low level of details.

Green, Orange \& Light blue: Visibility, no permeability e.g., podium landscape, feature mostly not mapped

Yellow: publicly accessible semi-indoor space and indoor space, inconsistently mapped Darkblue. mixing one axial line and two axial lines mapping of two sides of the street.

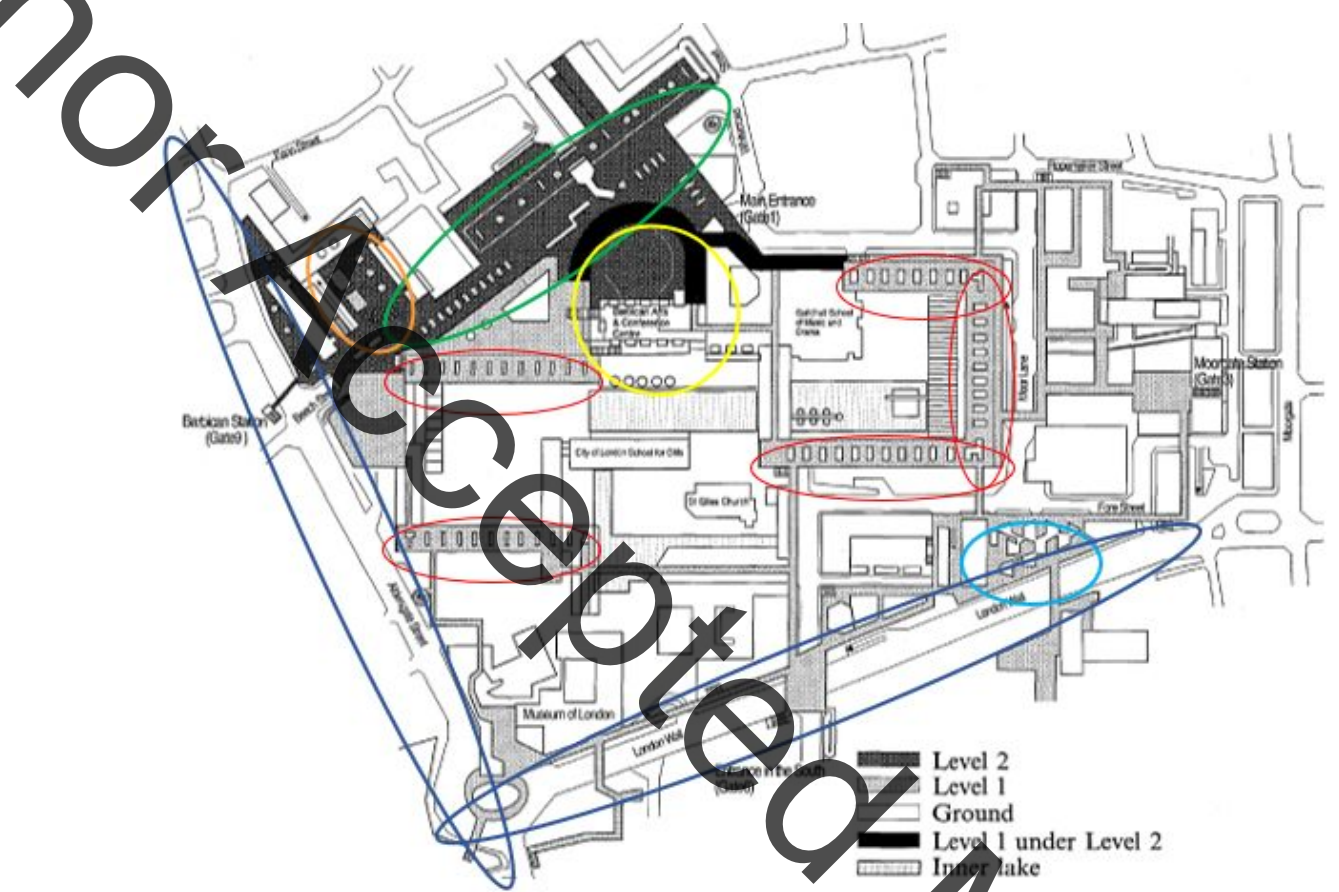

Figure S10. Source: adapted from Chang \& Penn 1998.

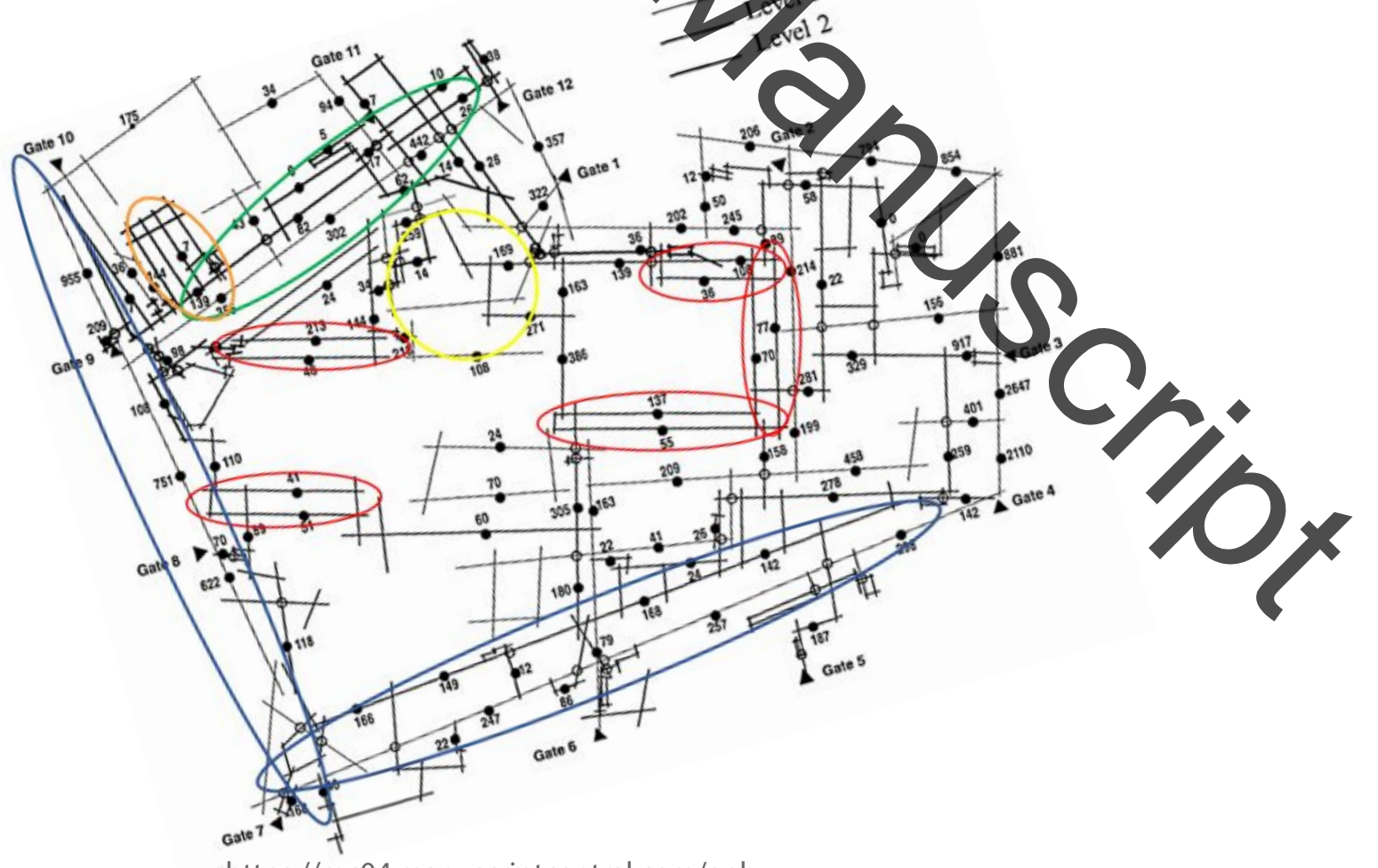




\section{S11: Four spatial models of pedestrian network}

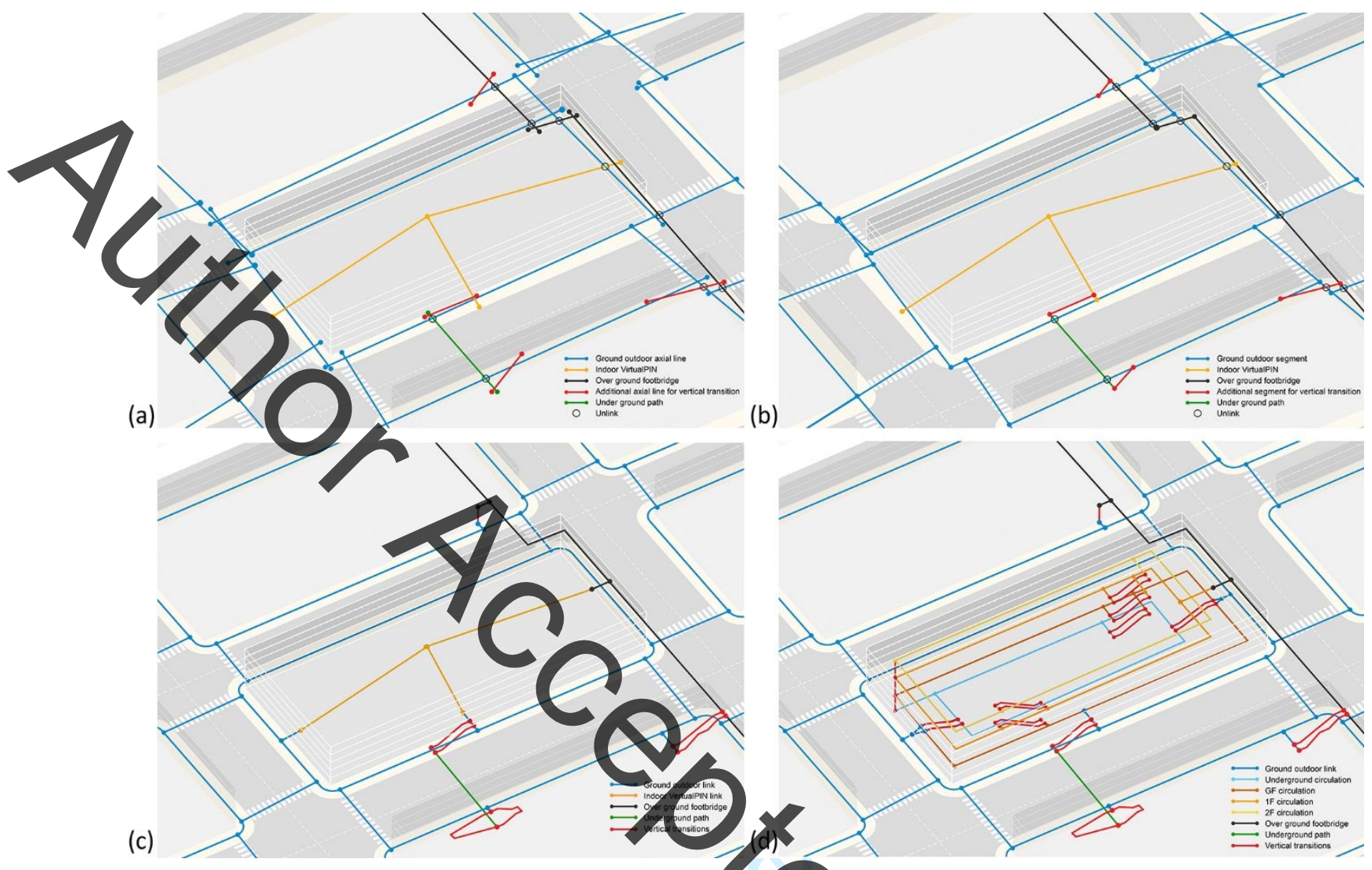

Figure S11. Four spatial models of pedestrian network:

space syntax, 2.5D-depthmap software: a. Spatial model (3) and (3v): (3) 2.5D Axial map - outdoor at grade, skywalk, below ground indoor, unlinks, (3v) PIN in orange, and added line as vertical transition; $\mathbf{b}$. Spatial model (4) and (4v): (4) 2.5D Segment map - derived from Axyal map, (4v) PIN in orange.

3D-sDNA software: c. Spatial model (5) and (5v): (5) 3D Path-centre line map outdoor at grade, below ground, skywalk, escalator, lift, ramp, stairway, and (5v) PIN in orange, d. Spatial model (6): 3D Pathcentre line map outdoor and full multi-level indoor with vertical transition: escalator, lift, ramp, and stairway.

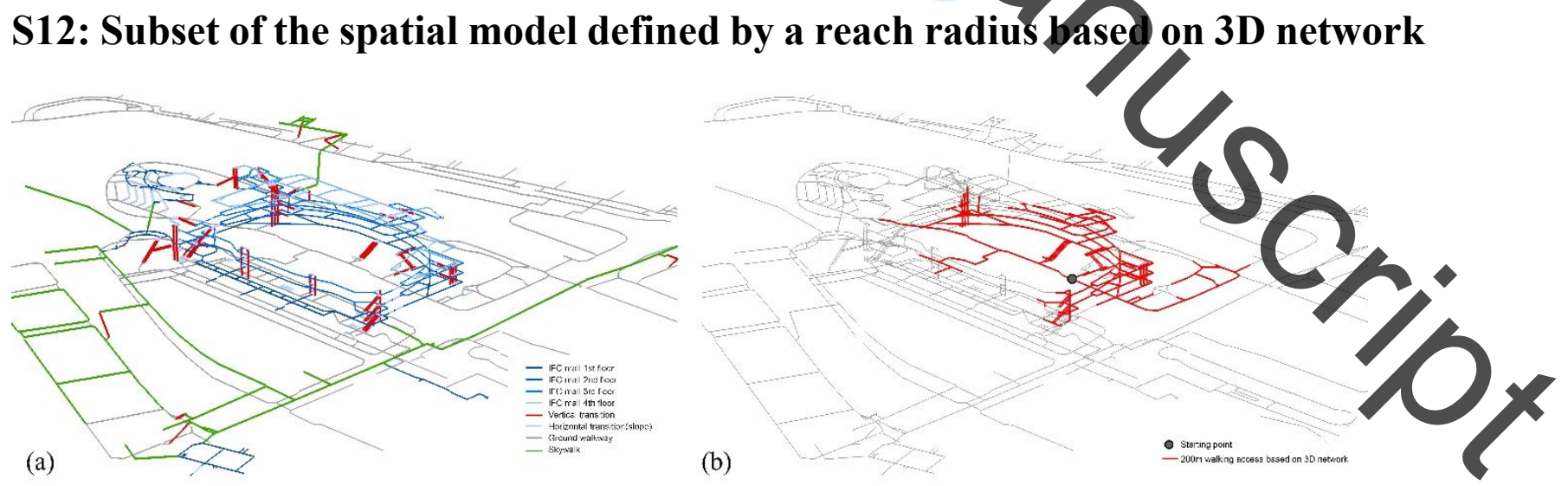

Figure S12. a. Spatial model (6): 3D indoor-outdoor network of IFC mall; b. Spatial model (6): Illustration of 3D spherical $400 \mathrm{~m}$ radius. 


\section{S13: All results of Bivariate Regression Analysis between observed pedestrian flow and betweenness \& closeness measures according to each radius}

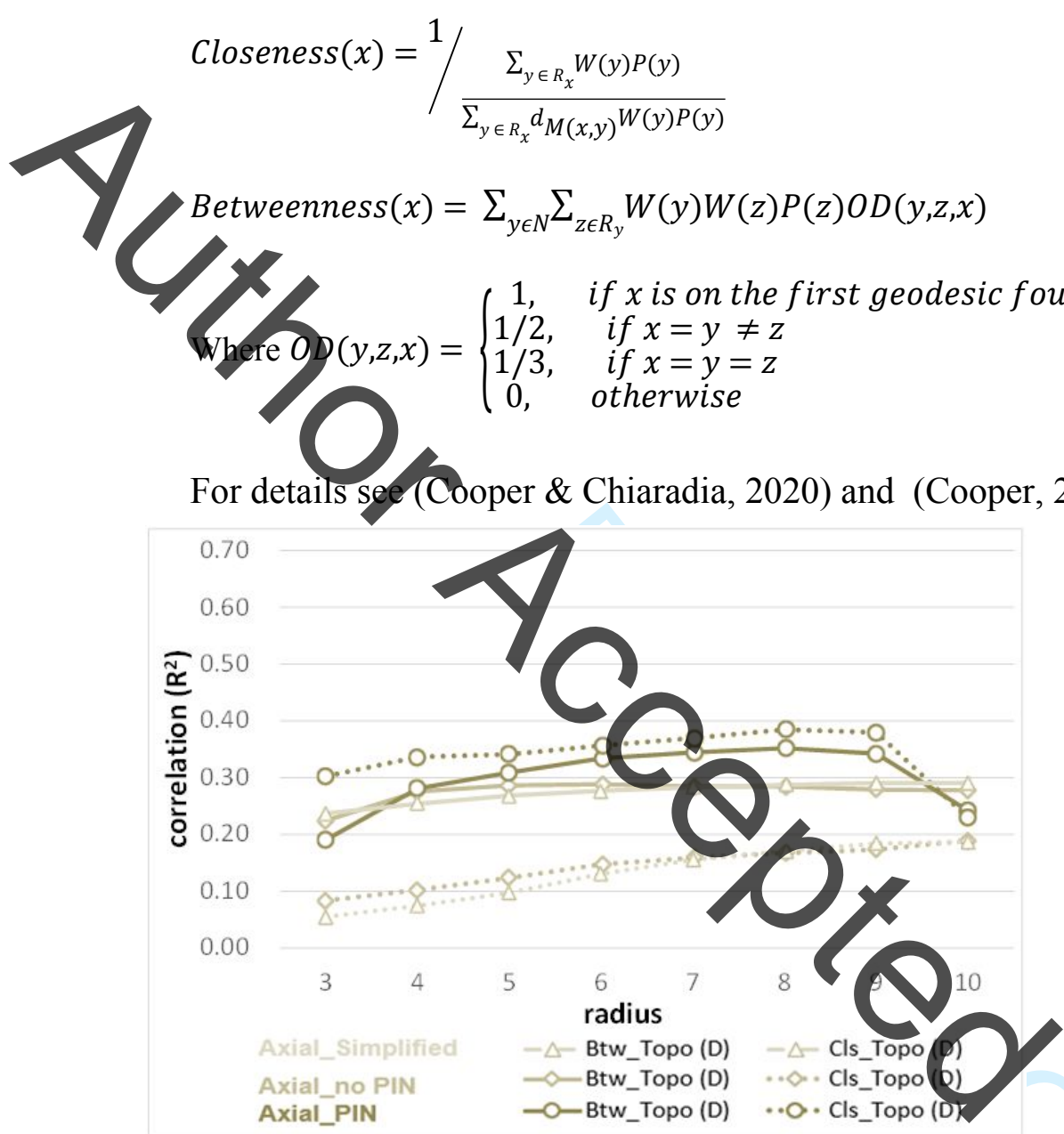

Figure S13a: Spatial model (1): Axial map standard (simplified i.e., aggregated), Spatial model (3) Axial map disaggregated with two sides of the street without PIN (outdoor only) and Spatial model (3v) disaggregated with two sides of the street and with PIN (Pedestrian Indoor Network - simplified). Adding two sides of the street and the PIN increase level of correlation $\left(\mathrm{R}^{2}\right)$ with observed pedestrian flows. 
Segment_Simplified Segment_noPIN Segment_PIN 3D Outdoor no PIN 3D Outdoor PIN 3D Outdoor\&Indoor 0.70

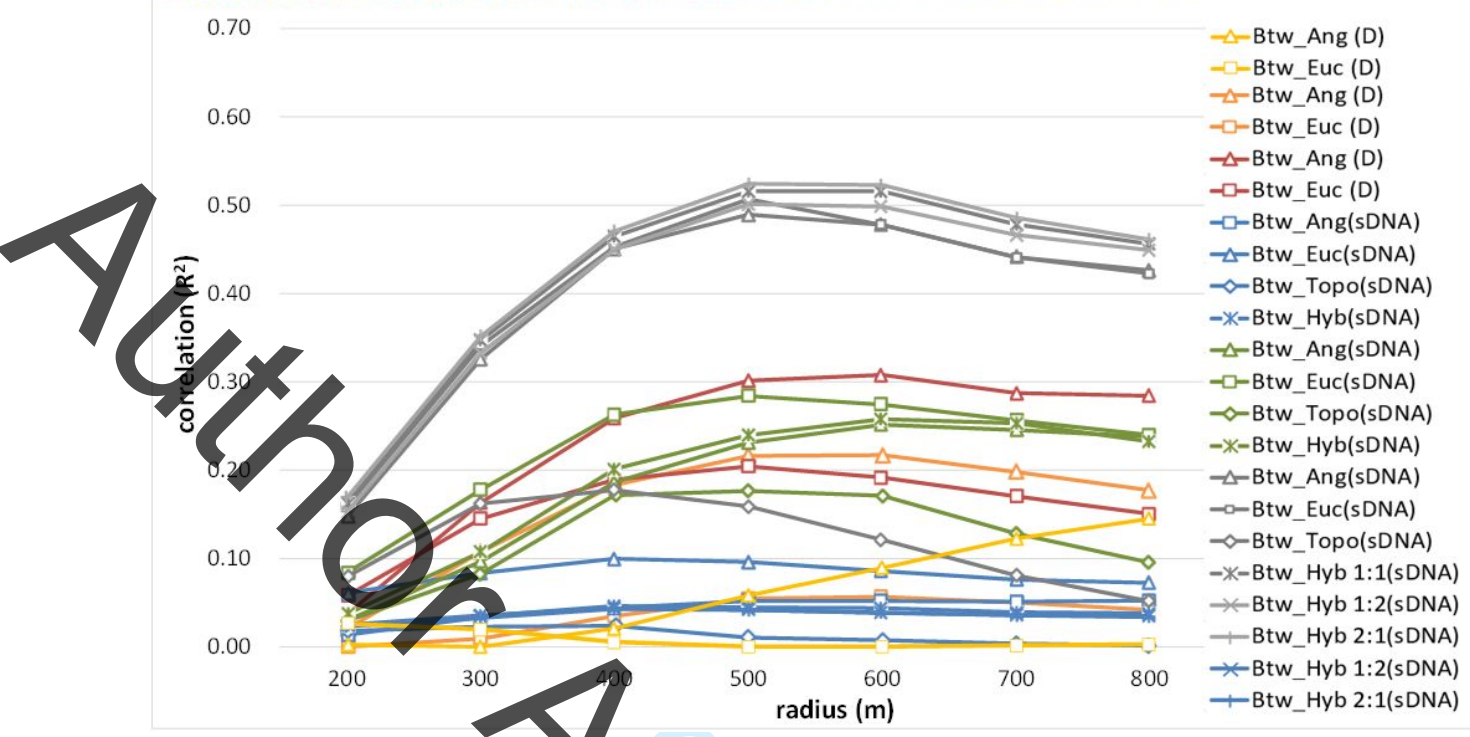

Figure S13b: Betweenness - Most correlations (R2) increase until radius 500-600 m are reached and then start to decrease. For most spatial model, the pattern is well behaved, except for Axial angular which increase constantly as radius increase.

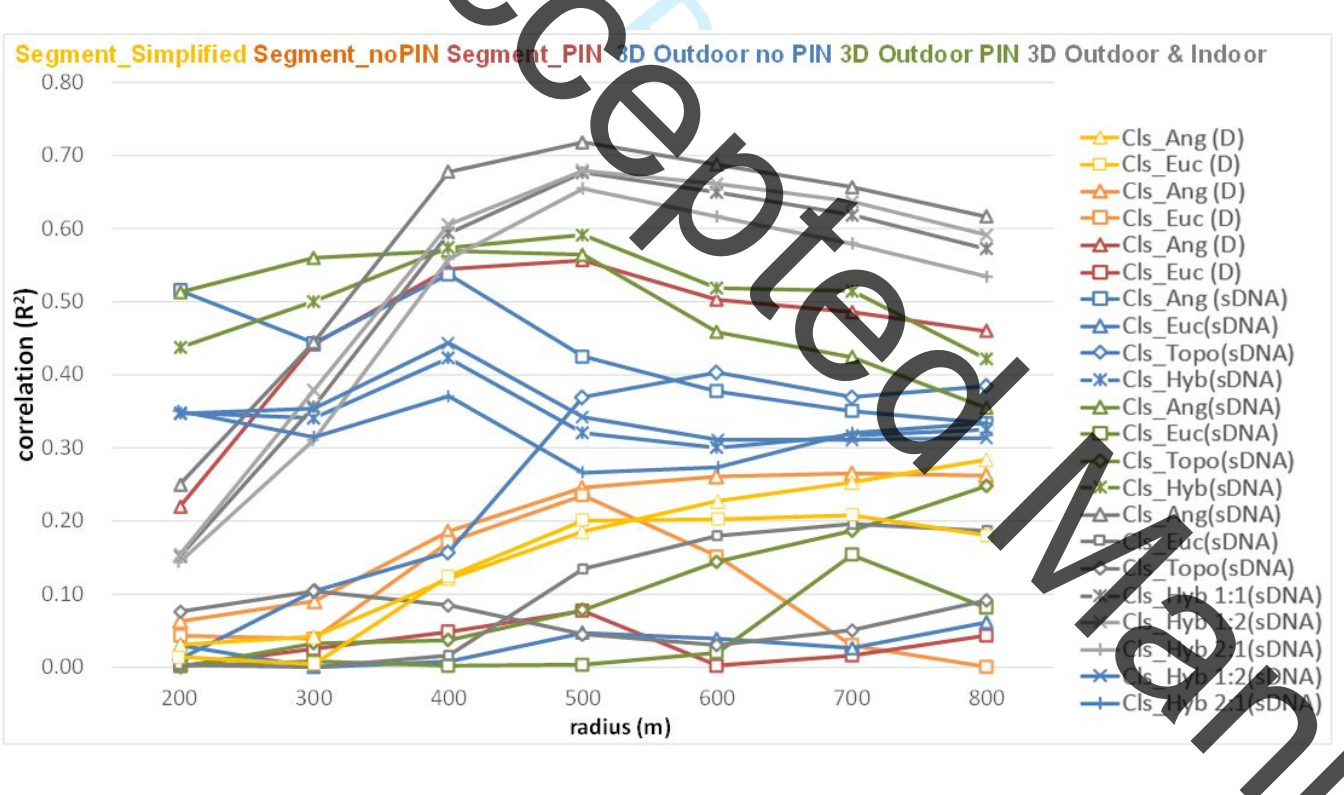

Figure S13c: Closeness - correlations (R2) also peak at radius 500-600 m. The patterns are irregular, except for sDNA Hybrid analysis (most direct and shortest).

\section{S14: Detailed Description of the results}

The first group of results (without PIN) compare the axial, derived segment, and 3D Outdoor path-centre line maps without the PIN, as they map the same pedestrian network wit different spatial models. This group is the most comparable to Chang and Penn (1998) It is apparent that in Hong Kong complex 3D environment, the axial line spatial model performs much better than expected, accounting for $\approx 29 \%$ of the variance while the "inherent intelligibility" is very low $0.085 \mid 0.285$ for the overall study area|count area respectively. In two 
areas in central London, the Barbican and Southbank, Chang and Penn's multi-level study (1998) show that with "inherent intelligibility" of $0.207 \mid 0.372$ and $0.412 \mid 0.607$ respectively, only $15 \%$ and $8 \%$ of the variance is accounted for by the analysis. For the $3 \mathrm{D}$ spatial model (5) (Table ST05), Betweenness, an expression of flow, is low while closeness, topological, angular and hybrid analysis account for about $\approx 37 \%$ and $54 \%$ of the variances. The coefficient of determination improves by up to $84 \%$. To note:

The mixed aggregated/desegregated axial and segment spatial models (1) and (2) (Table ST5) perform as well as the fully disaggregated spatial models (3) and (4) (Table ST5). This has very practical implications that could be extrapolated to path centre line spatial model. This requires further studies.

2. With the Hybrid andysis of the 3D spatial model (5) when weighting the Euclidean vs Angular along with the link from 2:1 to $1: 2$ the coefficient of determination changes from 0.371 to 0.444 . When using an equal weight, it is 0.423 . How the weighting affects the results requires further investigation.

The second group of results compares the variant spatial models with the PIN added (3v), $(4 \mathrm{v}),(5 \mathrm{v})$ (Table ST5). The PIN is an over-simplification of an indoor pedestrian path configuration. Generally, adding the PIN improves correlation substantially across the three spatial models. This is an indication of the importance of indoor and outdoor interdependencies in volumetric BEs. Again, the axial map performs relatively well (0.347). Betweenness for the axial line spatial model and topological analysis outperforms the segment and 3D spatial models. For closeness, the 3D link spatial model (5v) (Table ST05) perfons best, with an R-square $\approx$ 0.59 , marginally better than the segment map at $\approx 0.56$, and much better than the axial map at $\approx$ 0.38. This shows that the segment spatial model is an improvement as shown in Hillier and Iida (2005) but also that a path centre line is a spatial model that is at least equivalent or better.

The last column Table ST05 shows the results of the full 3D indoor and outeloor spatial model (6). It shows that the full 3D spatial model is better at capturing the movement pattern in a volumetric environment. Betweenness Euclidean $(1: 0, \mathrm{R} 2 \approx 0.51)$ and betweenness hybrid $(1 \% 2$ $\mathrm{R} 2 \approx 0.52)$ are marginally better than angular $(\approx 0.49)$. For closeness, $(1: 0, \mathrm{R} 2 \approx 0.72)$ and $(2: 1$, $\mathrm{R} 2 \approx 0.68$ ) show correlation levels usually found for 2D outdoor only urban conditions (H Iida, 2005; Cooper \& Chiaradia, 2015). In summary, correlation increases as spatial model realism and level of definition increase. 
Axial line spatial model and analysis, with and without a PIN, shows a moderate association, with a maximum $\mathrm{R}^{2}$ value of $\approx 0.38$. There is a significant improvement with the segment map and angular analysis $\left(\mathrm{R}^{2} \approx 0.56\right)$. The path-centre line map (outdoor only) shows a slightly better $\mathrm{R}^{2}$ with pedestrian movement flows than the segment map $\left(\mathrm{R}^{2} \approx 0.59\right)$. The full $3 \mathrm{D}$ spatial model, with a floor-by-floor indoor pedestrian network and the geometry of all the vertical transitions, shows $\mathrm{R}^{2}$ that increases from $\approx 0.59$ to $\approx 0.72$. The significant improvement of the R-square value parallels the increasing details of the spatial model, up to fully detailed 3D.

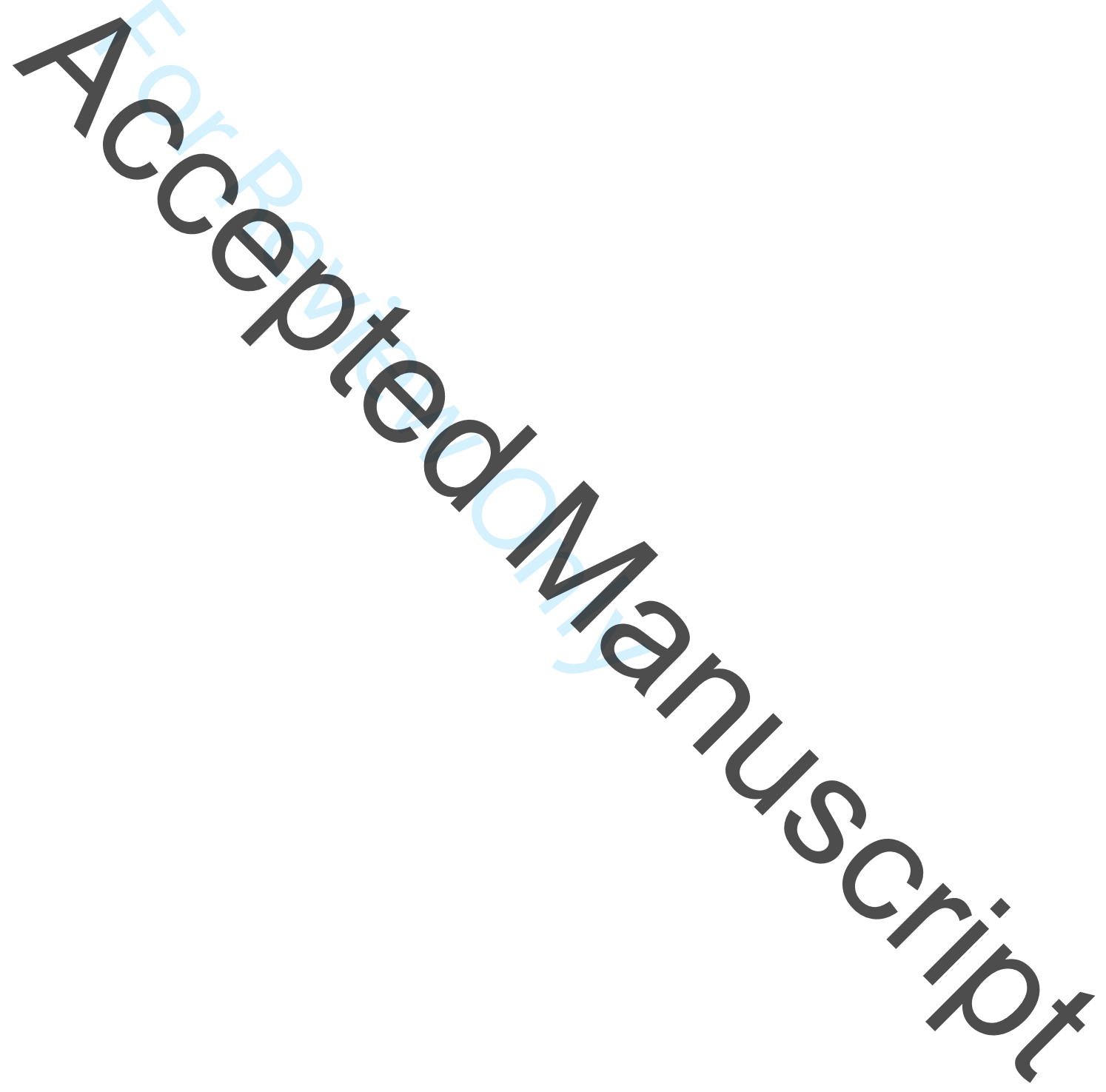


S15: Method of calculating volumetric density and network density within $400 \mathrm{~m}$ of each observation cordon

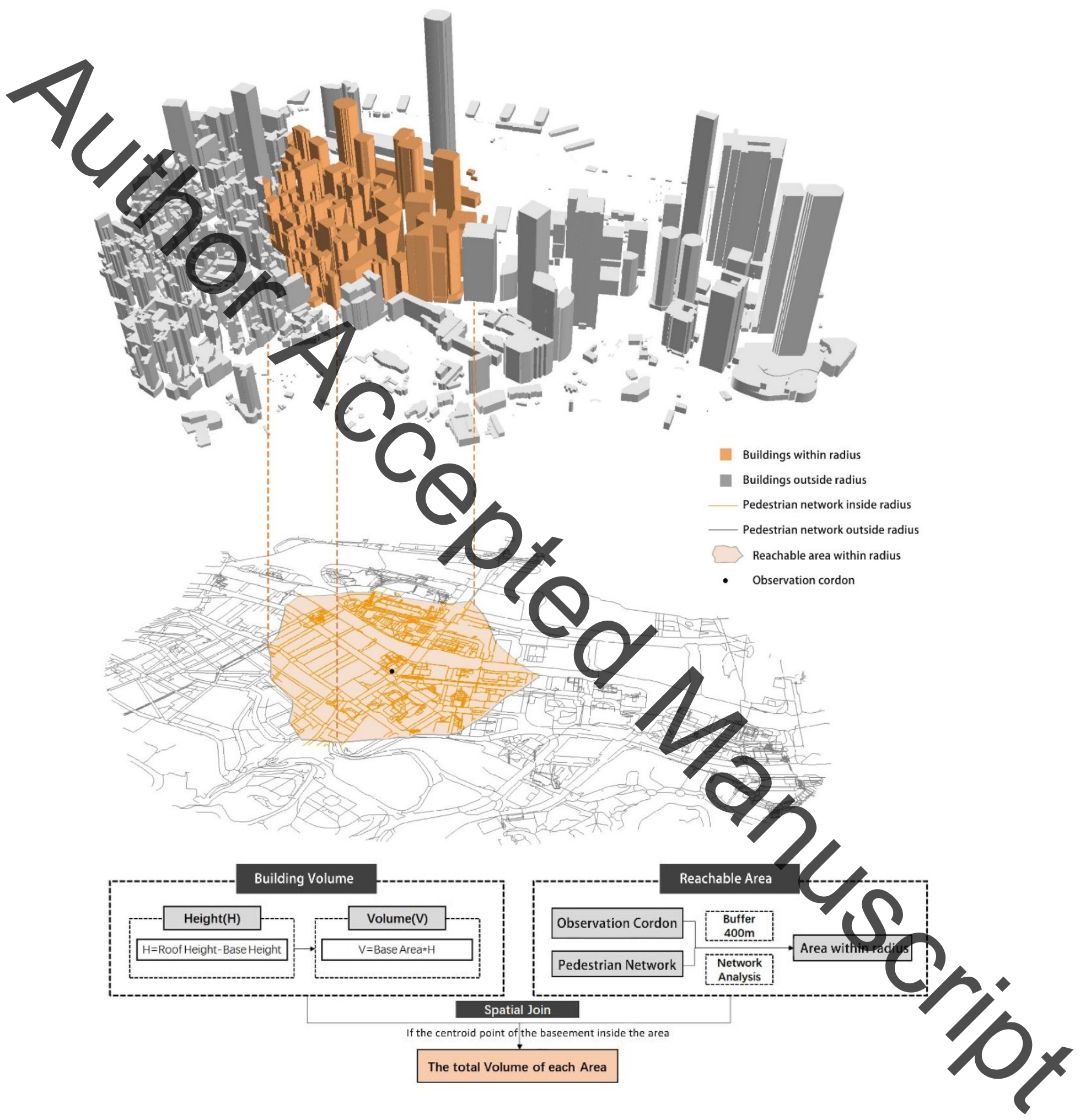

Figure S15: Principle of calculating density using a 3D model derived from HKSAR PlanD (2020). 
Figure S16: model of the role of morphological "inherent" intelligibility (left) and enactivism framework of intelligibility (right)

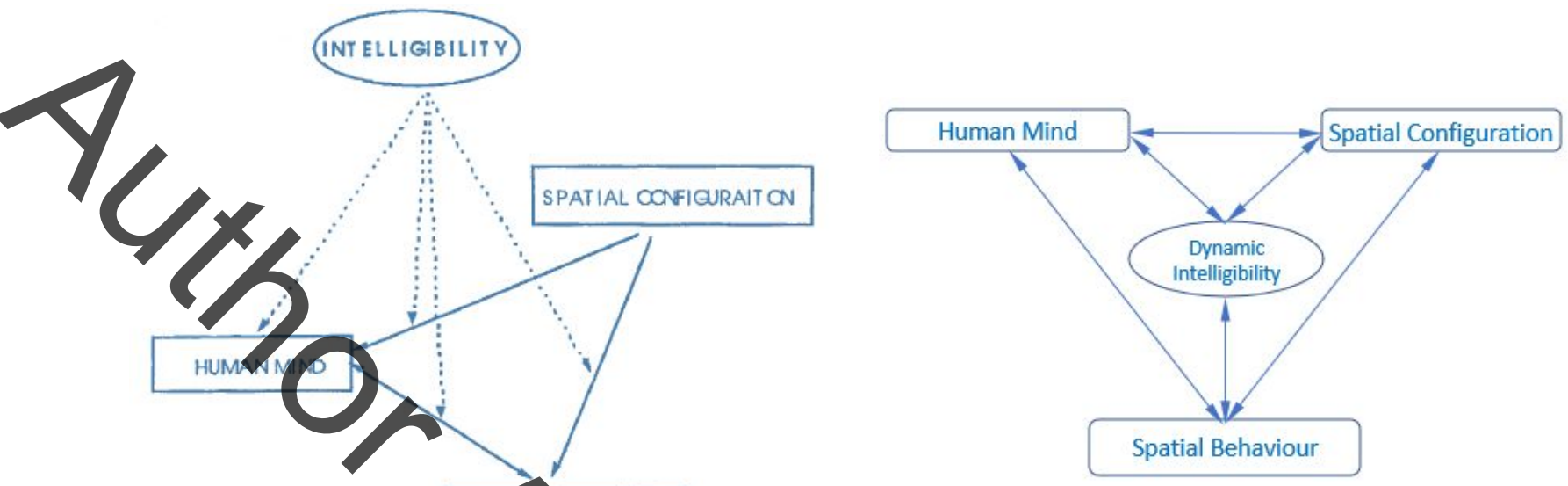

Invalid source specified.: Kin' (1999) model of the role of morphological "inherent" intelligibility in the interface between cognition and the environment

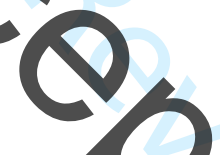

Enactivism framework of intelligibility: human beings and their environments stand in relation to each other through mutual specification or codetermination, and participate in the generation of meaning, engaging in transformational and not merely informational interactions (De Jaegher \& Rohde, 2010).

In London, the Barbican and South Bank are relatively exceptional. They are selected as an extreme case of built environment, as large-scale 3D multi-level-built environment in a mainly 2D street level-built environment. In Hong Kong, Central, while being exceptional in its 3D scale and complexity is also the main CBD and commercial area. Central is comparable, as an extreme case to the Barbican and South Bank in their complexity/unintelligibility to enable the discussion of "inherent intelligibility", yet the key difference is elsewhere. Central in HK, as the main CBD is well known and experienced by most people in Hong Kong. Central has also been used as "downsized model" that has been replicated for the "civic centre" of all the new towns where $60 \%$ of the Hong Kong population live. Thus, there is amilarity and adaptation to 3D built environment complexity that is likely not to be found in London. This is corrobarated by the findings of Coutrot et al. (2020) who report on spatial navigation ability showing that cities with grid layout (simple layout) have a negative impact on wayfinding capability, while wayfinding eapability is increasing with more complex organic cities, i.e., urban complexity is also related to increase in the level of spatial navigation ability. See also, Khun et al. (2020) on the difference between rural and urban children in relation to cognitive performance in spatial processing tasks.

As an alternative model to inherent intelligibility, we would suggest a "dynamic intelligibility index" or "cultural intelligibility index" that could be conceptualised within an enactivism framework (De Jaegher \& Rohde, 2010). Enactivism is a position in cognitive science that argues that cognition arises through a dynamic interaction between acting organisms and their environment - See Figure Si6 (tight) above. Within such a framework, we can hypothesize that people in Hong Kong have developed spatial cognition capacity and the ability to navigate $3 \mathrm{D}$ prevalent complexity/unintelligibility. These complexities have become internalised and intelligible thus explaining the relatively good predictability of
the axial line "standard" spatial model in HK. The space syntax "inherent intelligibility" index might be an index of complexity, yet it does not equate to inherent intelligibility or predictability. Simply put as a hypothesis, Hong Kong's multi-level-built complex environments are prevalent and part of the culture, thus intelligible, while there are not in London.

The above discussion, lead us to hypothesise that in the Barbican and South Bank if we were to compare spatial model, the 3D spatial model would still perform better, yet lower than in Hong Kong. 
1

2

3

4

5

6

7

8

9

Also, when including the indoor network, it would increase the level of accounted variances yet even a full 3D spatial model would not reach the same high level of the association because the "dynamic or cultural intelligibility" of such complex built environment is lower in London than in HK. These are important points for a new science of the cities and the science and art of designing cities.

\section{Table ST1. Link types with description and enumeration of the 3D indoor-outdoor path-} centre line map of the study area.

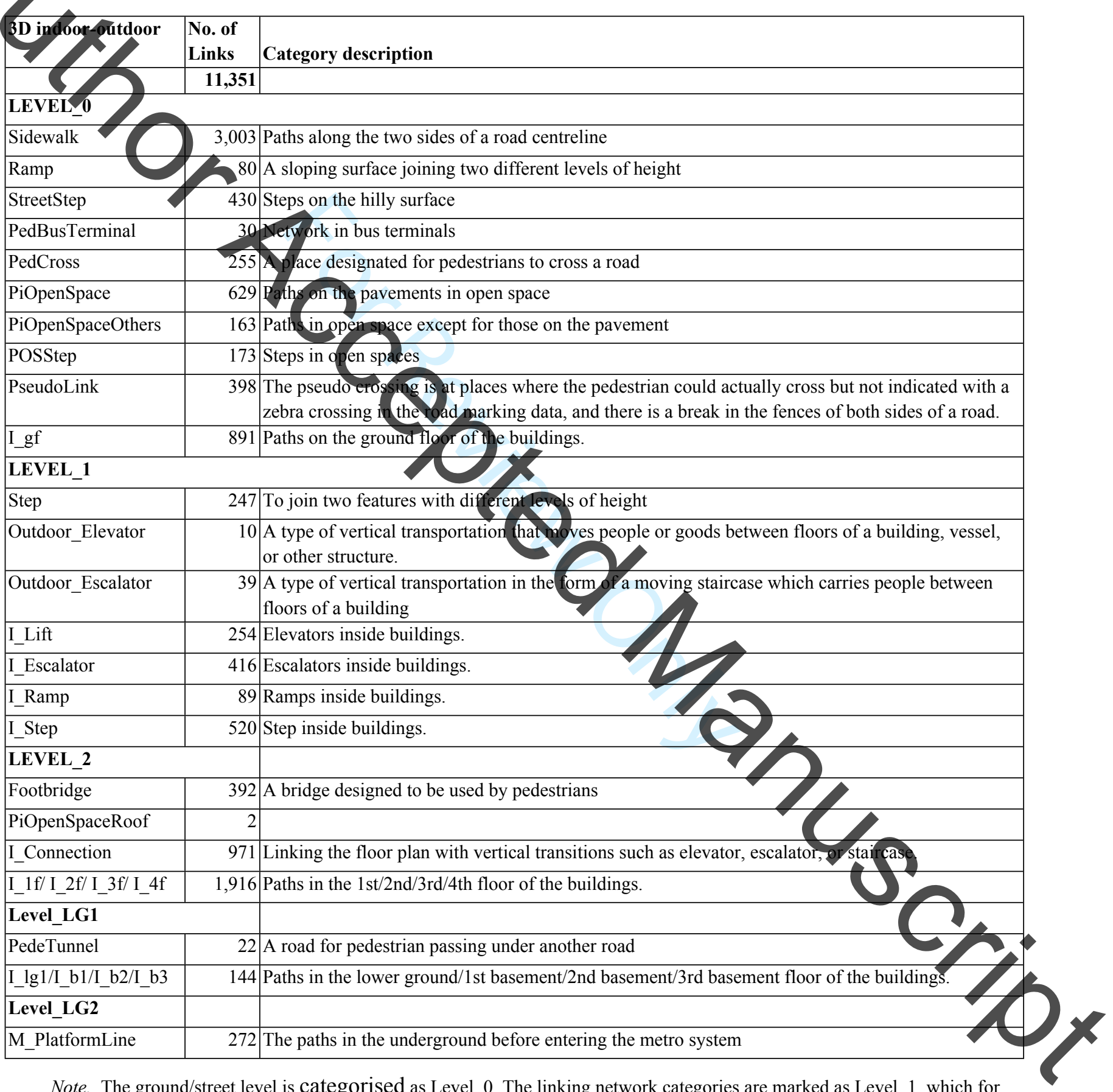
outdoor are linkages of the street with the above ground, for indoor are linkages between different floors. The categories on the above ground such as footbridges and all paths inside the buildings above ground floor are marked as Level_2. The categories underground such as pedestrian tunnels and all paths inside the buildings under ground floor are marked as Level LG1. Metro underground is marked as Level_LG2. 


\section{Network based cognitive urban volumetrics}

Table ST2: Summary of the literature review analysing spatial complexity using 3D visibility/isovist analysis.

- The studies analysing spatial complexity using visibility/isovist analytics are either indoor OR outdoor and do not mix indoor AND outdoor except for Bathia et al. (2013).

- These studies are not concerned with differentiating vertical transitions (lift, escalator, stair, ramp, and slope) except perhaps Morais et al. (2017). - These studies do not distinguish the two connectivity/permeability sides of the street and the crossings except for Desyllas et al. (2003) which is
outdoor only and 2D.

- Bathia et al. (2013) and Morais et al. (2017) do not investigate empirical movement patterns or/and wayfinding tasks.

- So far, empirical studies of the movementpattern, wayfinding/navigation have used Visual Graph Analysis (VGA) which can then be taken as paradigmatic for visibility/isovist empirical studies $\mathrm{VGA}$ is $2 \mathrm{D}$ and requires manually link vertical transition in different floor plans and does not differentiate vertical transitions (e.g., lift, escalator, stair, ramp, and slope).

\begin{tabular}{|c|c|c|c|c|c|c|c|c|c|c|c|c|c|c|c|c|}
\hline & \begin{tabular}{|c|} 
2D \\
Plan \\
\end{tabular} & \begin{tabular}{|c|} 
2.5D Stacked \\
Multi-level
\end{tabular} & $3 \mathrm{D}$ & \begin{tabular}{|c|} 
2D \\
Path
\end{tabular} & $\begin{array}{l}\text { Vertical } \\
\text { transition }\end{array}$ & VR & In & \begin{tabular}{|c|}
$\begin{array}{c}\text { Out } \\
\text { door }\end{array}$ \\
\end{tabular} & $\mathrm{I} \& \mathrm{O}$ & \begin{tabular}{|c|} 
Spatial \\
complexity
\end{tabular} & $\begin{array}{c}\text { Movement } \\
\text { pattern }\end{array}$ & Occupancy & \begin{tabular}{|l|} 
Wayfinding \\
Navigation \\
\end{tabular} & Spatial profile & \begin{tabular}{|c|} 
Spatial \\
analysis
\end{tabular} & $\begin{array}{c}\text { Software } \\
\text { implementation }\end{array}$ \\
\hline (Benedikt, 1979) & $\checkmark$ & $\checkmark$ & & $\checkmark$ & & & $x$ & $\checkmark$ & $\checkmark$ & $\checkmark$ & & & & House I \& O & & Not disclosed \\
\hline (Conroy \& Dalton, 2001) & $\checkmark$ & & & $\sqrt{ }$ & & & & 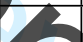 & & $\checkmark$ & & & & Tate & & Omnivista \\
\hline (Batty, 2001) & $\checkmark$ & & & $\checkmark$ & & & $\sqrt{ }$ & $\checkmark$ & & $\checkmark$ & & & & Urban, Tate & & StarLogo \\
\hline (Turner, et al., 2001) & $\checkmark$ & $\checkmark$ & & $\checkmark$ & & & & & & $\checkmark$ & & $\checkmark$ & & House, Tate & VGA & Not disclosed \\
\hline$($ Turner \& Penn, 2002)** & $\checkmark$ & & & & & & $\checkmark$ & & & $\checkmark$ & $\checkmark$ & & & Tate & VGA & EVA/Dephtmap ${ }^{1,2}$ \\
\hline$($ Desyllas, et al., 2003)*** & $\checkmark$ & & & & & & & $\checkmark$ & & $\checkmark$ & $\sqrt{ }$ & & & Urban & VGA & Proprietary \\
\hline (Wiener \& Franz, 2005) & $\checkmark$ & & & & & $\checkmark$ & $\checkmark$ & & & $\checkmark$ & & & $\checkmark$ & Gallery & VGA & Anavis \\
\hline (Wiener, et al., 2007) & $\checkmark$ & & & & & $\checkmark$ & $\checkmark$ & & & 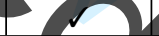 & & & $\checkmark$ & Gallery & VGA & Anavis \\
\hline (Yang, et al., 2007) & $\checkmark$ & & $\checkmark$ & & & & & $\checkmark$ & & $\checkmark$ & & & & Urban & & GIS \\
\hline (Derix \& Gamlesæter, 2008) & $\checkmark$ & & $\checkmark$ & & & & & $\sqrt{ }$ & & $\bar{\gamma}$ & & & & Urban & & Proprietary \\
\hline (Parvin, et al., 2008) & 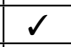 & $\checkmark$ & & & & & $\checkmark$ & $\checkmark$ & & $\sqrt{2}$ & & & & Urban, I \& O & VGA & Depthmap $^{2}$ \\
\hline (Morello \& Ratti, 2009) & $\checkmark$ & & $\checkmark$ & $\checkmark$ & & & & $\checkmark$ & & $\checkmark$ & & & & Urban & & Not disclosed \\
\hline (Meilinger, et al., 2012) & $\checkmark$ & & $\checkmark$ & $\sqrt{ }$ & & $\checkmark$ & & $\checkmark$ & & 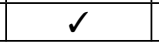 & & & $\checkmark$ & Urban & VGA & Ajanachara \\
\hline (Bhatia, et al., 2013) & $\checkmark$ & & $\checkmark$ & $\sqrt{ }$ & $\sqrt{ }$ & & & & $\checkmark$ & $\sqrt{ }$ & & & & House, I \& O & & Sketchup \\
\hline (Suleiman, et al., 2013) & $\checkmark$ & & $\checkmark$ & & & & & $\checkmark$ & & $\checkmark$ & & & & Urban & & Matlab/GIS \\
\hline (Koltsova, et al., 2013) & $\checkmark$ & & $\checkmark$ & $\sqrt{ }$ & & & & $\checkmark$ & & $\sqrt{2}$ & & & & Urban & & Rhino \\
\hline (Fisher-Gewirtzman, et al., 2013) & $\checkmark$ & & $\checkmark$ & & & & & $\checkmark$ & & $\checkmark$ & & & & Urban & & Not disclosed \\
\hline (Varoudis \& Psarra, 2014) & 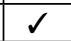 & & $\checkmark$ & & & & $\sqrt{ }$ & & & 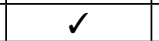 & & & & Office & & Sketchup \\
\hline (Conroy \& Dalton N, 2015)* & $\sqrt{2}$ & & $\checkmark$ & & & & $\sqrt{ }$ & & & $\sqrt{1}$ & & & & Room & & Not disclosed \\
\hline (Lonergan \& Hedley, 2016)* & $\checkmark$ & & $\checkmark$ & $\checkmark$ & & & & $\checkmark$ & & $\sqrt{2}$ & & & & Urban & & GIS \\
\hline (Izaki \& Derix, 2017)* & $\sqrt{4}$ & $\sqrt{ }$ & $\checkmark$ & $\sqrt{2}$ & & & $\checkmark$ & $\sqrt{ }$ & & $\checkmark$ & & & & Mall, Urban & & Proprietary \\
\hline (Chang \& Park, 2018) & $\checkmark$ & & $\checkmark$ & & & & & $\checkmark$ & & $\checkmark$ & & & & Urban & & TVA \\
\hline (Lu, et al., 2019) & $\checkmark$ & & $\checkmark$ & & & & $\checkmark$ & $\checkmark$ & & $\checkmark$ & & & & an or Indoor & & ArcGIS \\
\hline (Kim, et al., 2019) & $\checkmark$ & & $\checkmark$ & & & & & $\checkmark$ & & $\checkmark$ & & & & Urban & & ArcGIS 3D Pro \\
\hline (Krukar, et al., 2020) & $\sqrt{2}$ & & $\checkmark$ & & & $\checkmark$ & $\sqrt{ }$ & & & $\checkmark$ & & & & $y_{n}$ & & Not disclosed \\
\hline
\end{tabular}


Table ST3. Descriptive statistics of all 33 observed cordon counts.

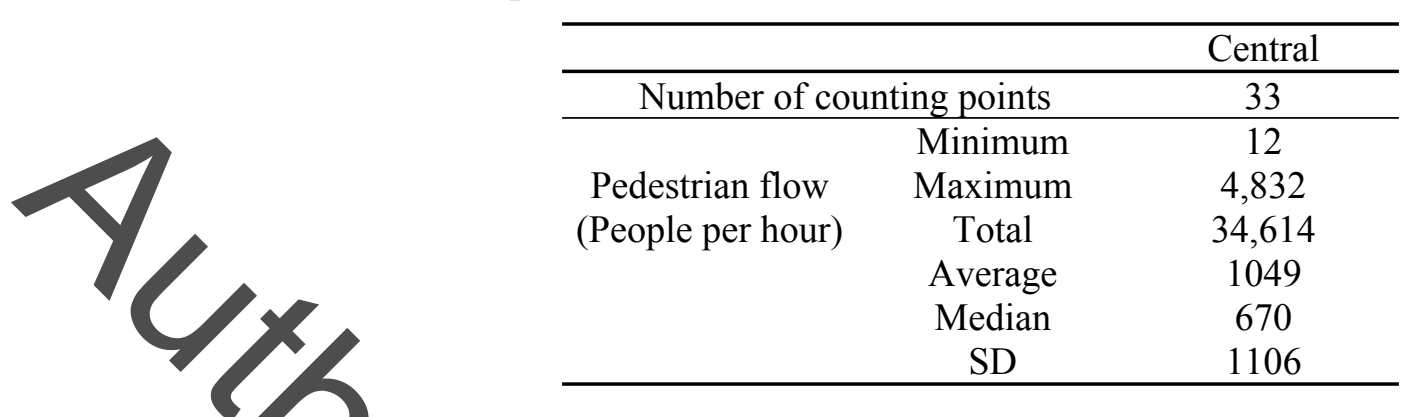

Table ST4. Descriptive statistics of Axial map 2.5D (v3) and (v4), segment map $2.5 \mathrm{D}, 3 \mathrm{D}$ outdoor path-centre line map, and complete $3 \mathrm{D}$ indoor and outdoor pathcentre line map.

- the axial line map is aggregated compared to the segment map, 3,699 lines versus 7,193

- the segment map seems to suffer for over desegregation in particular for links that are curvilinear Figure S02b), the segment map has about 20\% more segment than link for the outdoor path centre line spatial model.

- Outdoor only (v5) vs outdoor and publicly accessible indoor (v6), show that omitting the indoor will create a very incomplete spatial model. 
Table ST5. Bivariate Regression Analysis, highest R-square coefficient of determination between Ln pedestrian movement and Ln betweenness/Ln Closeness measures for the nine spatial models, $(\mathrm{N}=33)$.

\begin{tabular}{|c|c|c|c|c|c|c|c|c|c|c|c|}
\hline \multirow[t]{3}{*}{ Analysis } & \multicolumn{2}{|c|}{ Analysis Metric } & Generalised & andard" axial) & \multicolumn{7}{|c|}{ Two sides of the street - Level of Definition } \\
\hline & & \multirow{2}{*}{$\begin{array}{c}\text { Angular/ } \\
\text { Euclidean } \\
\text { metric }\end{array}$} & $\begin{array}{l}\text { (1) Axial } \\
\text { 2.5D }\end{array}$ & $\begin{array}{l}\text { (2) Segment } \\
2.5 \mathrm{D}\end{array}$ & $\begin{array}{c}\text { (3) Axial map } \\
2.5 \mathrm{D}\end{array}$ & $\begin{array}{c}\text { (4) Segment ma } \\
2.5 \mathrm{D}\end{array}$ & (5) 3D Outdoor & $\begin{array}{l}\text { (3v) Axial map } \\
\text { 2.5D }\end{array}$ & $\begin{array}{c}\text { (4v) Segment map } \\
2.5 \mathrm{D}\end{array}$ & $\begin{array}{l}\text { (5v) 3DPN } \\
\text { 3D }\end{array}$ & \multirow{2}{*}{$\begin{array}{c}\text { (6) 3DPN } \\
\text { 3D } \\
\text { Outdoor \& Indoor } \\
\end{array}$} \\
\hline & & & \multicolumn{5}{|c|}{ Without Pedestrian Indoor Network (Without PIN) - outdoor only } & \multicolumn{3}{|c|}{ With PIN - simplified indoor } & \\
\hline \multirow{6}{*}{$\begin{array}{l}\text { Betwee } \\
\text { nness }\end{array}$} & Topological & NA & $0.291(\mathbf{R} 10)^{* *}$ & & $0.288(\mathbf{R 6})^{* *}$ & NA & $0.023(\mathrm{R} 400)$ & $0.347(\mathrm{R} 7)^{* *}$ & NA & $0.177(\mathrm{R} 500)^{*}$ & $0.177(\mathrm{R} 400)^{*}$ \\
\hline & Angular & $1: 0$ & NA & 0 & NA & $0.217(\mathrm{R} 600)^{* *}$ & $0.052(\mathrm{R} 500)$ & NA & $0.308(\mathrm{R} 600)^{* *}$ & $0.252(\mathrm{R} 600)^{* *}$ & $0.489(\operatorname{R500})^{* *}$ \\
\hline & Euclidean & $0: 1$ & NA & $6(\mathrm{R}$ & NA & $0.057(\mathrm{R} 600)$ & $0.096(\mathrm{R} 500)$ & NA & $0.204(\mathrm{R} 500)^{* *}$ & $0.284(\mathrm{R} 500)^{* *}$ & $0.507(\mathbf{R 5 0 0})^{* *}$ \\
\hline & Hybrid & $1: 1$ & NA & NA & $A$ & NA & $0.046(\mathrm{R} 400)$ & NA & NA & $0.258(\mathrm{R} 600)^{* *}$ & $0.516(\mathrm{R} 500)^{* *}$ \\
\hline & Hybrid & $1: 2$ & NA & NA & & NA & 0.044 (R400) & NA & NA & $0.256(\mathrm{R} 600)^{* *}$ & $0.524(\mathrm{R} 500)^{* *}$ \\
\hline & Hybrid & $2: 1$ & NA & NA & & NA & 0.043 (R400) & NA & NA & $0.256(\mathrm{R} 600)^{* *}$ & $0.501(\mathrm{R} 500)^{* *}$ \\
\hline \multirow{6}{*}{$\begin{array}{l}\text { Closen } \\
\text { ess }\end{array}$} & Topological & NA & $\mathbf{0 . 1 8 7 ( \mathrm { R } 1 0 )}{ }^{*}$ & NA & $0180(\mathrm{P} 1$ & NA & $0.403(\mathrm{R} 600)^{* *}$ & $\mathbf{0 . 3 8 4}(\mathrm{R} 8)^{* *}$ & NA & $0.145(\mathrm{R} 600)^{*}$ & 0.085 (R400) \\
\hline & Angular & $1: 0$ & NA & $0.284(\mathrm{R} 800)^{*}$ & & $2600)^{* *}$ & $\mathbf{0 . 5 3 7}(\mathrm{R} 400)^{* *}$ & NA & $\mathbf{0 . 5 5 6}(\mathrm{R} 500)^{* *}$ & $\mathbf{0 . 5 7 0}(\mathrm{R} 600)^{* *}$ & $0.718(\mathrm{R} 500)^{* * *}$ \\
\hline & Euclidean & $0: 1$ & NA & 0.208 (R700) & NA & & $0.047(\mathrm{R} 500)^{* *}$ & NA & 0.077 (R500) & $0.020(\mathrm{R} 600)$ & 0.180 (R600)* $^{*}$ \\
\hline & Hybrid & $1: 1$ & NA & NA & NA & & $0.423(\mathrm{R} 400)^{* *}$ & NA & NA & $0.591(\mathrm{R} 500)^{* *}$ & $0.677(\mathrm{R} 500)^{* *}$ \\
\hline & Hybrid & $1: 2$ & NA & NA & NA & & $0.444(\mathrm{R} 400)^{* *}$ & NA & NA & $0.578(\mathrm{R} 500)^{* *}$ & $0.654(\mathrm{R} 500)^{* *}$ \\
\hline & Hybrid & $2: 1$ & NA & NA & NA & & $0.371(\mathrm{R} 400)^{* *}$ & NA & NA & $0.575(\mathrm{R} 500)^{* *}$ & $0.679(\mathrm{R} 500)^{* *}$ \\
\hline
\end{tabular}

Note. Axial \& segment maps were computed by Space Syntax software (DepthmapX), outdoor only \& indoor-outdoor path-centre line maps were computed by Spatial Design Network Analysis (sDNA). Betweenness and closeness measures were analysed at radius R3 to 7 for axial map, and radius $200,300, \ldots, 800 \mathrm{~m}$ for segment and path-centre line maps, numbers in round parenthesis indicate the best radius.

The correlation between observed pedestrian flow and betweenness \& closeness measures according to each radius is shown in Figure S13.

$* p \leq 0.05$ level. $* * p \leq 0.01$ level.

The difference between mixed aggregated/disaggregated and fully disaggregated axial lineand related segment spatial models ((1) \& (2) vs (3) \&(4)) give similar results $\mathrm{R}^{2} \approx 0.29$, while the addition of the PIN (simplified indoor network) make $\mathrm{a}+113 \%$ difference to $\mathrm{R}^{2} \approx 0.56$ between space syntax $(4 \mathrm{v}) \&(4 \mathrm{v})$ spatial models. Adding PIN to $3 \mathrm{D}$ transport geography spatial model (5) inerease by $10 \%$ to $\mathrm{R}^{2} \approx 0.59(5 \mathrm{v})$ and to $\mathrm{R}^{2}$ $\approx 0.72$ (6v) for adding a full indoor network with similar level of significance

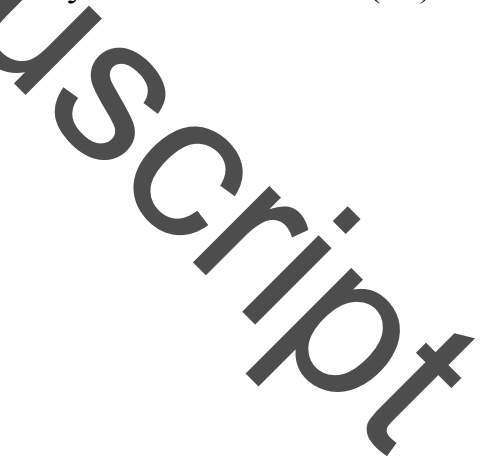




\section{Table ST6. Multivariate Stepwise Regression Analysis Results.}

Model Summary

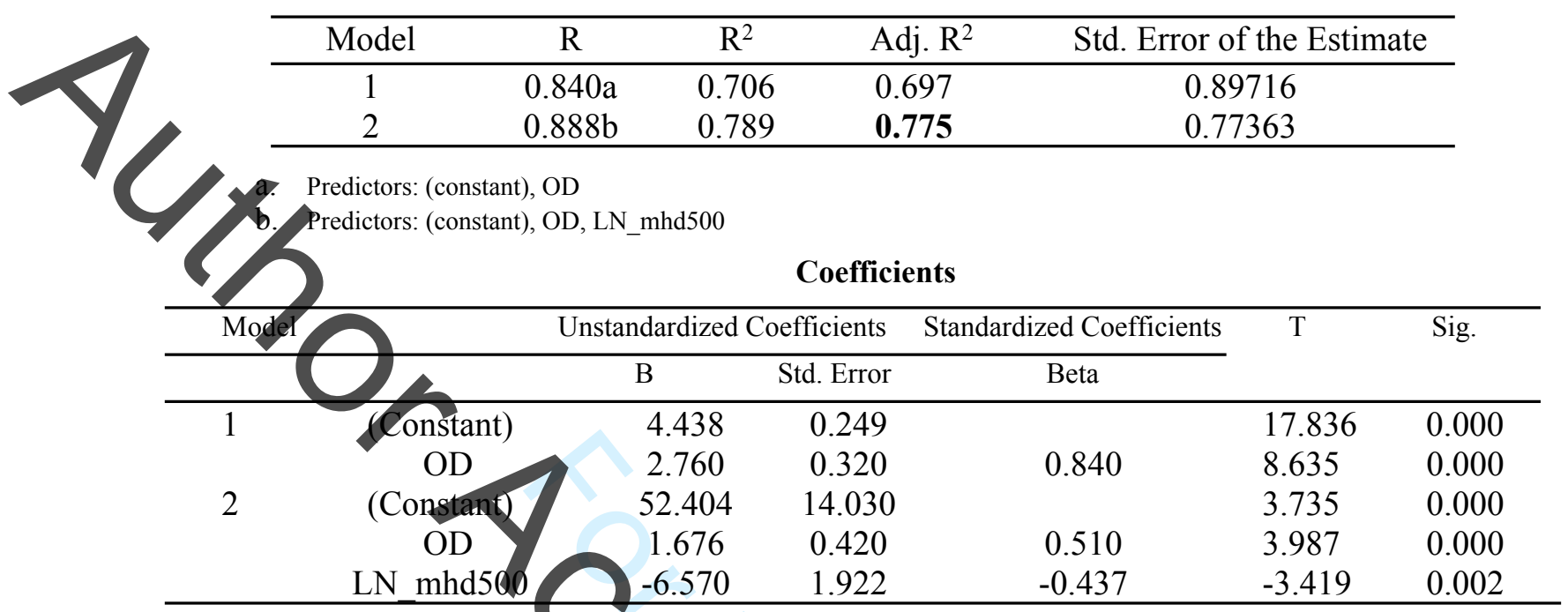

a. Dependent variable: LN pedestrian flow.

As found previously (Marchand, 1974, p. 12; Marchand, 1977) distance from attractors generators is significant. It also shows that people that are familiar with an area will approximate the shortest path which are often also the most direct (Table 1). Yet, as the number of attractors/generators increases, closeness hybrid (mhd) all to all within radius 500 $\mathrm{m}$, seems to be able to capture the complex relationship between shortest path and most direct in $3 \mathrm{D} \mathrm{I} / \mathrm{O} \mathrm{BE}$.

\section{Normality test of the residuals}

$\mathrm{A}=$ Standardized residual value of regression a (for Table 2 in the manuscript):

The dependent variable is Ln Pedestrian movement, the independent variable is Angular Closeness measure at $500 \mathrm{~m}$ radius.

$\mathrm{B}=$ Standardized residual value of regression $\mathrm{b}$ (for Table 2 in the manuscript):

The dependent variable is Ln Pedestrian movement, the independent variable is Hybrid Betweenness measure at $500 \mathrm{~m}$ radius. $\mathrm{C}=\mathrm{Standardized}$ residual value of the stepwise regression (for Table 3 in the manuscript):

Tests of Normality

\begin{tabular}{|l|c|c|c|c|c|c|}
\hline \multirow{2}{*}{ Course } & \multicolumn{3}{|c|}{ Kolmogorov-Smirnov ${ }^{\mathrm{a}}$} & \multicolumn{3}{c|}{ Shapiro-Wilk } \\
\cline { 2 - 7 } & Statistic & df & Sig. & Statistic & df & Sig. \\
\hline Standardized Residual A & 0.098 & 33 & $.200^{*}$ & .960 & 33 & .259 \\
Standardized Residual B & 0.104 & 33 & $.200^{*}$ & .973 & 33 & .565 \\
Standardized Residual C & 0.134 & 33 & .141 & .937 & 33 & .054 \\
\hline
\end{tabular}

a. Lilliefors Significance Correction

* This is a lower bound of the true significance.

Tests of Normality table shows that the Sig. value of the Shapiro-Wilk Test is greater than 0.05 , the data can be considered to have a normal distribution. 
Network based cognitive urban volumetrics

\section{References}

- Batty, M., 2001. Exploring isovist fields: space and shape in architectural and urban morphology. Environment and planning B: Planning and Design, 28(1), pp. 123-150.

- Benedikt, M. L., 1979. To take hold of space: isovists and isovist fields. Environment and Planning B: Planning and design, 6(1), pp. 47-65.

- Bhatia, S., Chalup, S. \& Ostwald, M., 2013. Wayfinding: a method for the empirical evaluation of structural saliency using 3D Isovists. Architectural Science Review, 56(3), pp. 220-231.

Chang, D. \& Park, J., 2018. Quantifying the Visual Experience of Three-dimensional Built Environments. Journal of Asian Architecture and Building Engineering, 17(1), pp. 117-124. Chang, D. \& Penn, A., 1998. Integrated multilevel circulation in dense urban areas: the effect of multiple interacting constraints on the use of complex urban areas. Environment and Planning B: Planning and Design, 25(4), pp. 507-538.

- Conroy, R. \&Dalton, N., 2001. Omnivista: An application for isovist field and path analysis. In: J. Peponus, J. Wineman \& S. Bafna, eds. 3rd Space Space International Symposium. Atlanta: Ann Arbor College of Arehitecture \& Urban Planning, University of Michigan, MI, pp. 25.1-25.10.

- Conroy, R. D. \& Dalton N, S., 2015. The problem of representation of 3D isovists. In: K. Karimi, et al. eds. Proceedings of the 10th Space Syntax International Symposium, London. London: Space Syntax Laboratory, Dhe Bartlett School of Architecture, UCL (University College London), pp. 141.1-141.14.

- Cooper, C., 2016. Spatial Design Network Analysis (sDNA) Manual version 3.4. [Online] Available at: https://sdna.cardiff.ac.uk/sdna/wpcontent/downloads/documentation/mantral/sDNA_manual_v3 4 5/index.html [Accessed 0106 2021].

- Cooper, C. \& Chiaradia, A., 2015 sDNA hou and why we reinvented spatial network analysis for health, economics and active mode of transport. Leeds, Leeds University - Figshare, pp. 122-127.

- Cooper, C. H. V. \& Chiaradia, A. J. F., 2020. SDNA: 3d Spatial Network Analysis for GIS, CAD, Command Line \& Python. SoftwareX, pp. 1-24.

- De Jaegher, H. \& Rohde, M., 2010. Enaction: Toward a new paradigm for cognitive science. Cambridge, Mass: MIT Press.

- depthmapX development team, 2017-19. SpaceGroupUCL-depthmapX v0.8.0 [Computer software]. [Online] Available at: //github.com/SpaceGroupUCL/depthmapX/ [Accessed 10 2021].

- Derix, C. \& Gamlesæter, Å., 2008. 3d Isovists and Spatial Sensations: Tyomethods and a case study. In: S. Haq, H. Hölscher \& S. Torgrude, eds. Environmental Design Research Association 39th Annual Conference: Movement and Orientation in Built Environments. Evaluating Design Rationale and User Cognition. Veracruz, Mexico: EDRAMOVE \& SFB TR8, pp.67-72.

- Desyllas, J., Duxbury, E., Ward, J. \& Smith, A., 2003. Pedestrian Demand Modelling of Large Cities, an Applied Example from London. In: Proceedings of the 8th International Conference on Computers in Urban Planning and Urban Management. Sendai: The Center for Northeast Asian Studies, Tohoku University.

- Fisher-Gewirtzman, D., Shashkov, A. \& Doytsher, Y., 2013. Voxel based volumetric visibility analysis of urban environments. Survey Review, 45(333), pp. 451-461.

- Flyvbjerg, B., 2001. Making social science matter: Why social inquiry fails and how it can succeed again. Cambridge: Cambridge University Press.

- Hanson, J., 1994. 'Deconstructing' architects' houses. Environment and Planning B: Planning and Design, 21(6), pp. 675-704.

- Hanson, J., 1998. Decoding Homes and Houses. Cambridge: Cambridge University Press.

- Hillier, B. \& Hanson, J., 1984. The Social Logic of Space. Cambridge: Cambridge University Press. 
- Hillier, B. \& Iida, S., 2005. Network effects and psychological effects: a theory of urban movement. In: G. Cohn A \& M. Mark D, eds. Spatial Information Theory. COSIT 2005. Lecture Notes in Computer Science, vol 3693. Berlin, Heidelberg: Springer, pp. 475-490.

- HKSAR BD, 2020. Building Records Access and Viewing On Line. [Online] Available at: https://bravo.bd.gov.hk/login.action [Accessed 06 2019].

- HKSAR LandsD, 2020. 3D Pedestrian Network, Hong Kong: HKSAR.

- Hölscher, C., Brösamle, M. \& Vrachliotis, G., 2012. Challenges in Multilevel Wayfinding: A Case Study with the Space Syntax Technique. Environment and Planning B: Urban Analytics and City Science, 39(1), pp. 63-82.

Å. \& Derix, C., 2017. Evolution of Planning with Visual Conditions. In: B. Piga \& R. Salemo, eds. Urban Design and Representation. Cham: Springer, pp. 83-98.

- Kim, G., Kim, A. \& Kim, Y., 2019. A new 3D space syntax metric based on 3D isovist capture in urban space using remote sensing technology. Computers, Environment and Urban Systems, Volume 74, pp. 74-87.

- Koltsova, A., Tunçer, B. \& Schmitt, G., 2013. Visibility Analysis for 3D Urban Environments. In: R. Stouffs \& S. Sariyildiz, eds. Models of Computation: Human Factors - Volume 2 Computation and Performance - eCAADe. Delft: eCAADe and Faculty of Architecture, Delft University of Technology, p. 375-384.

- Krukar, J., Manivannan, C., Bhatt, M. \& Schultz, C., 2020. Embodied 3D isovists: A method to model the visual perceptron of space. Environment and Planning B: Urban Analytics and City Science, p. p. 2399808320974533

- Kühn, S. et al., 2020. Brain structure and habitat: Do the brains of our children tell us where they have been brought up?. Neurolmage, Votume 222, p. 117225.

- Lonergan, C. \& Hedley, N., 2016. Unpacking isovists: a framework for 3D spatial visibility analysis. Cartography and Geographic Information Science, 43(2), pp. 87-102.

- Lu, Y., Gou, Z., Ye, Y. \& Sheng, Q., 2010. Three-dimensional visibility graph analysis and its application. Environment and Planning B: Urban Analytics and City Science, 46(5), pp. 948-962.

- Marchand, B., 1974. Pedestrian traffic planning and the perception of the urban environment: a French example. Environment and Planning A, 6(5), pp. 491-507.

- Marchand, B., 1977. Planning Pedestrian Flows around a Subytay Station: A French Case Study of the Time-Distance Decay Functions. Geographical Analysls, 9(1),pp. 42-50.

- Meilinger, T., Franz, G. \& Bülthoff, H., 2012. From isovists via mental representations to behaviour: first steps toward closing the causal chain. Environment and Planning B: Planning and Design, 39(1), pp. 48-62.

- Morais, F. et al., 2017. July. 3D Space Syntax Analysis. Case Study, Casa Da Musica. In: T. Heitor, ed. Proceedings of the 11th Space Syntax International Symposium. Lisbon: Lisbon Instituto Superior Técnico, Departamento de Engenharia CivilArquitetura Ce Georrecursos, pp. 121.

- Morello, E. \& Ratti, C., 2009. A digital image of the city: 3D isovists in Lynchis urban analysis. Environment and Planning B: Planning and Design, 36(5), pp. 837-853.

- Parvin, A., Min, A. \& Beisi, J., 2008. Effect of visibility on multilevel movement: a study of the high-density compact built environment in Hong Kong. Urban Design International, 13(3), 169-181.

- $\quad$ Spencer, C. \& Wedderburn, M., 2007. Measuring Pedestrian Activity, London: Transport for London \& CBuchanan.

- Suleiman, W., T, J. \& Favier, E., 2013. A New Algorithm for 3D Isovists. In: S. Timpf \& P. Laube, eds. Advances in Spatial Data Handling. Advances in Geographic Information Science. Berlin, Heidelberg: Springer, pp. 157-173.

- Turner, A., 2007. From Axial to Road-Centre Lines: A New Representation for Space Syntax and a New Model of Route Choice for Transport Network Analysis. Environment and Planning B: Planning and Design, 34(3), pp. 539-555. 
- Turner, A., Doxa, M., O'Sullivan, D. \& Penn, A., 2001. From isovists to visibility graphs: a methodology for the analysis of architectural space. Environment and Planning B: Planning and Design, 28(1), pp. 103-121.

- Turner, A. \& Penn, A., 2002. Encoding natural movement as an agent-based system: an investigation into human pedestrian behaviour in the built environment. Environment and planning B: Planning and Design, 29(4), pp. 473-490.

- Turner, A., Penn, A. \& Hillier, B., 2005. An Algorithmic Definition of the Axial Map. Environment and Planning B: Planning and Design, 32(3), pp. 425-444. Varoudis, T. \& Psarra, S., 2014. Beyond two dimensions: architecture through three dimensional visibility graph analysis. The Journal of Space Syntax, 5(1), pp. 91-108. Wener, J. \& Franz, G., 2005. Isovists as a means to predict spatial experience and behavior. In: C. Freksa, et al. eds. Spatial Cognition IV. Reasoning, Action, Interaction. Spatial Cognition 2004. Lecture Notes in Computer Science vol 3343. Berlin: Springer, pp. 42-57.

- Wiener, J et al., 2007. Isovist analysis captures properties of space relevant for locomotion and experience. Perception, 36(7), pp. 1066-1083.

- Yang, P., Putra, S. \& Li, W., 2007. Viewsphere: a GIS-based 3D visibility analysis for urban design evaluation Environment and Planning B: Planning and Design, 34(6), pp. 971-992.

- Zhang, L. \& Chiaradia A, J., 2019. From axial to pedestrian path-centre line. The case of 3D Pedestrian Network in Hong Kong, Central. In: Proceedings12th International Space Syntax Symposium, 8-13 July 2019, Beijing, China.. Beijing: Sejong University Press, pp. 208.1-208.11.

- Zhang, L. \& Chiaradia, A, 2019. Three-dimensional Spatial Network Analysis and Its Application in a High Density City Area, Central Hong Kong. Urban Planning International, 33(1), pp. 46-53. 
Figure S08b. Correlation flow rates among all-day average and each period (Central, 33 cordons).
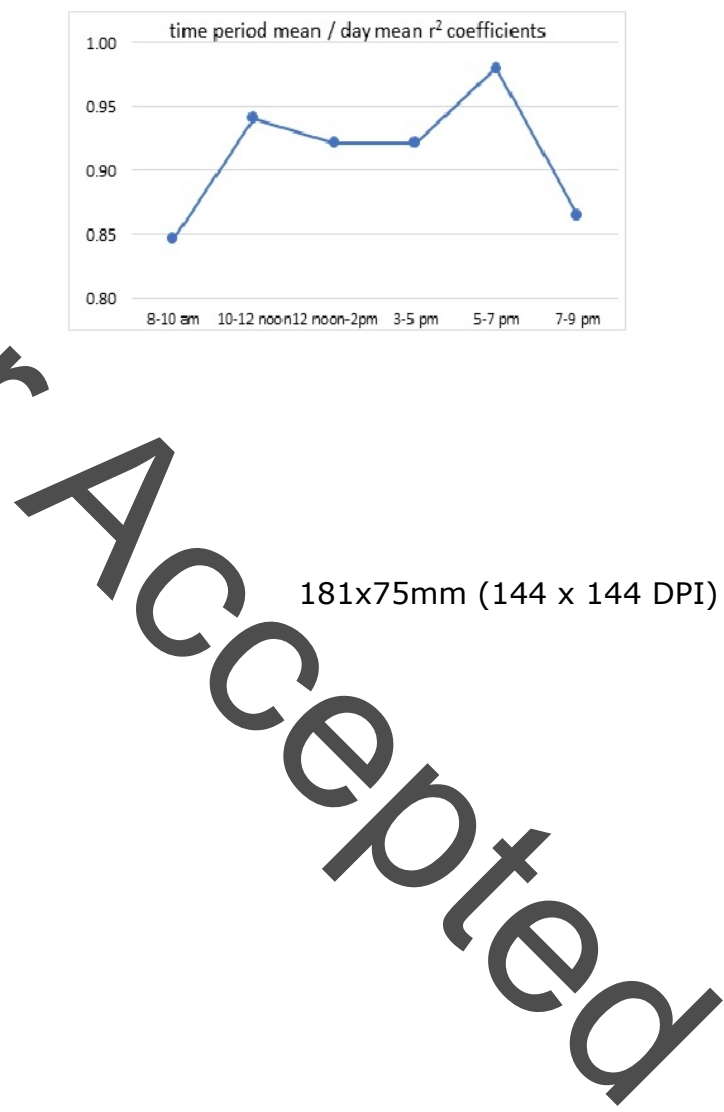